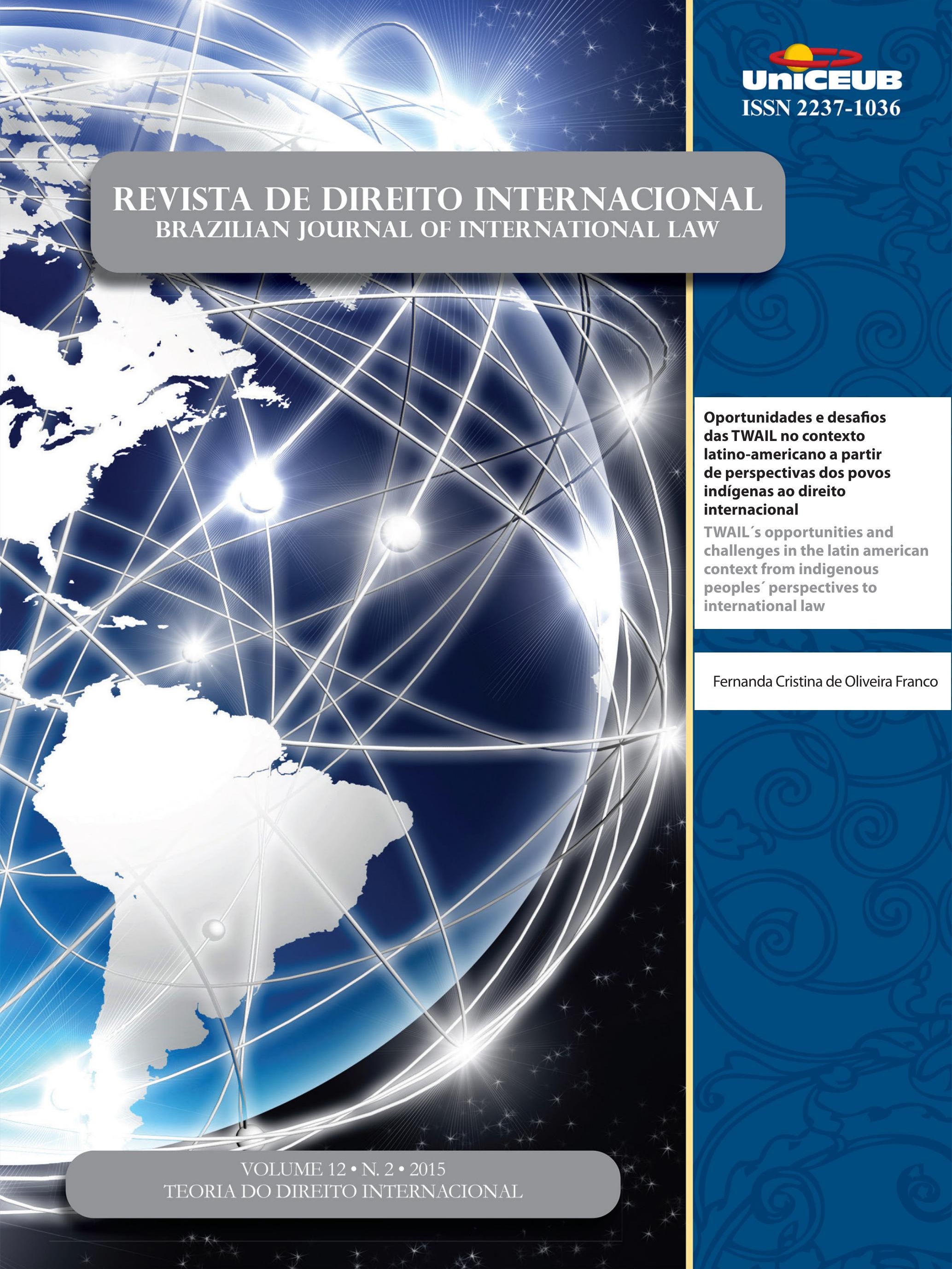




\section{Sumário}

CrôNiCAS DA ATUALIDADE do DiREITo INTERnACIONAL ..................................................... 2 Sarah Dayanna Lacerda Martins Lima, Carina Costa de Oliveira e Erika Braga

CrôniCas do Direito InternaCional dos InVESTIMENTOS ..............................................12 Nitish Monebhurrun

Por que voltar a Kelsen, o jurista do século XX ? 16 Inocêncio Mártires Coelho

O Princípio da Efetividade como conteúdo da norma fundamental (GrundNorm) DE KELSEN

Carlos Alberto Simões de Tomaz e Renata Mantovani de Lima

A JURIDIFICAÇÃo DE CONFLITOS POLÍTICOS NO DIREITO INTERNACIONAL PÚBLICO CONTEMPORÂ-

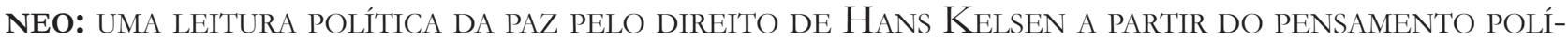
TICO De Claude Lefort

Arthur Roberto Capella Giannattasio

O SINCRETISMO TEÓRICO NA APROPRIAÇÃO DAS TEORIAS MONISTA E DUALISTA E SUA QUESTIONÁVEL UTILIDADE COMO CRITÉRIO PARA A CLASSIFICAÇÃO DO MODELO BRASILEIRO DE INCORPORA-

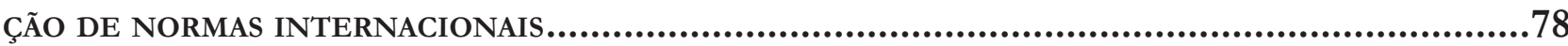
Breno Baía Magalhães

Direito Global em Pedaços: Fragmentação, Regimes e Pluralismo .98 Salem Hikmat Nasser

Por uma TeOria JURÍdica da INTEGRaÇão REgIONAL: A INTER-RELAÇÃO DiREITO INTERNO, DiREITO INTERNACIONAL PÚBLICO E DIREITO DA INTEGRAÇÃO Jamile Bergamaschine Mata Diz e Augusto Jaeger Júnior

A teOria DA INTERCONSTITUCIONALIDADE: UMA ANÁlISE COM BASE NA AMÉRICA LATINA...........160 Daniela Menengoti Ribeiro e Malu Romancini 
O DIÁLOGO HERMENÊUTICO E A PERGUNTA ADEQUADA À APLICAÇÃo DOS TRATADOS INTERNACIONAIS DE DIREITOS HUMANOS NO BRASIL: CAMINHOS PARA O PROCESSO DE INTERNACIONALIZAÇÃO

DA CONSTITUIÇÃO...................................................................................... 176

Rafael Fonseca Ferreira e Celine Barreto Anadon

O DIREITO COMPARADO NO STF: INTERNACIONALIZAÇÃO DA JURISDIÇÃO CONSTITUCIONAL BRASILEIRA

Carlos Bastide Horbach

THE PHILOSOPHY OF INTERNATIONAL LAW IN CONTEMPORARY SCHOLARSHIP: OVERCOMING NE-

GLIGENCE THROUGH THE GLOBAL EXPANSION OF HUMAN RIGHTS

Fabrício Bertini Pasquot Polido, Lucas Costa dos Anjos e Vinícius Machado Calixto

OpORTUNIDADES E DESAFIOS DAS TWAIL NO CONTEXTO LATINO-AMERICANO A PARTIR DE PERSPECTIVAS DOS POVOS INDÍGENAS AO DIREITO INTERNACIONAL

Fernanda Cristina de Oliveira Franco

Por Que uma ANÁlise ECONÔMICA Do DIREITO INTERNACIONAL PÚBLICO? DESAFIOS E PERSPECTIVAS DO MÉTODO NO BRASII

Gustavo Ferreira Ribeiro e Jose Guilherme Moreno Caiado

ANÁliSE ECONÔMICA do DIREITO INTERNACIONAL .263 Michele Alessandra Hastreiter e Luís Alexandre Carta Winter

RACIONALIDADE ECONÔMICA E OS ACORDOS BILATERAIS DE INVESTIMENTO 284 Michele Alessandra Hastreiter e Luís Alexandre Carta Winter

LOOKING FOR A BRICS PERSPECTIVE ON INTERNATIONAL LAW .304 Gabriel Webber Ziero

A INFLUÊNCIA DO DIREITO DESPORTIVO TRANSNACIONAL NO ORDENAMENTO JURÍDICO BRASILEIRO: DA REPRODUÇÃO DE NORMAS À APLICAÇÃO DIRETA PELA JURISDIÇÃO ESTATAL.......................3324 Tiago Silveira de Faria

CONVENCIONALIZAÇÃo DO DIREITO CIVIL: A APLICAÇÃo DOS TRATADOS E CONVENÇÕES INTERNACIONAIS NO ÂMBITO DAS RELAÇÕES PRIVADAS . 
NATIONAL JUdGES AND COURTS AS INSTITUTIONS FOR GLOBAL ECONOMIC GOVERNANCE 356

Juízes e tribunais nacionais como instituições para a governança global 356 Camilla Capucio

Is Trade Governance Changing? 371 Alberto do Amaral Júnior

OS FUNDOS ABUTRES: MEROS PARTICIPANTES DO CENÁRIO INTERNACIONAL OU SUJEITOS PERANTE O DIREITO INTERNACIONAL? 384

Guilherme Berger Schmitt

SHAREHOLDER AGREEMENTS IN PUBLICLY TRADED COMPANIES: A COMPARISON BETWEEN THE

U.S. AND BRAZIL. 402 Helena Masullo

REgulaÇÃo DO INVESTIMENTO ESTRANGEIRO DIRETO NO BRASIL: DA RESISTÊNCIA AOS TRATADOS BILATERAIS DE INVESTIMENTO À EMERGÊNCIA DE UM NOVO MODELO REGULATÓRIO 421 Fabio Morosini e Ely Caetano Xavier Júnior

DA QUALIFICAÇÃo JURÍDiCA dAS Distintas FORMAS DE PRESTAÇão TECNOLÓGICA: BREVE ANÁLISE DO MARCO REGULATÓRIO INTERNACIONAL

Daniel Amin Ferraz

REDEFINING TERRORISM: THE DANGER OF MISUNDERSTANDING THE MODERN WORLD'S GRAVEST THREAT

Jennifer Breedon

As EXECUÇões SELETIVAS E A RESPONSABILIZAÇÃo DE AGENTES TERRORISTAS 485 Alexandre Guerreiro

INTERNATIONAL CRIMINALS AND THEIR VIRTUAL CURRENCIES: THE NEED FOR AN INTERNATIONAL EFFORT IN REGULATING VIRTUAL CURRENCIES AND COMBATING CYBER CRIME Joy Marie Virga

Criminalidad transnacional organizada en el Ámbito del MERCOSUR: ¿Hacia un Derecho Penal Regional?. .528 Nicolás Santiago Cordini e Mariano Javier Hoet 
RUMO À INTERNACIONALIZAÇÃo DA PROTEÇÃO PENAL DO MEIO AMBIENTE: DOS ECOCRIMES AO ECOCÍDIO

Kathia Martin-Chenut, Laurent Neyret e Camila Perruso

Engaging the U.N. Guiding Principles on Business and Human Rights: the inter-AMERICAN COMMISSION ON HUMAN RIGHTS \& THE EXTRACTIVE SECTOR 571 Cindy S. Woods

O DIREITO HUMANO À COMUNICAÇÃo PRÉVIA E PORMENORIZADA DAS ACUSAÇÕES NOS PROCESSOS administrativos: O desprezo do Superior Tribunal de Justiça ao Pacto de San José da Costa Rica e À Corte Interamericana de Direitos Humanos .590

Daniel Wunder Hachem e Eloi Pethechust

A responsabilidade internacional do Brasil em FaCe do CONTRole de ConVENCionaliDADE EM SEDE DE DIREITOS HUMANOS: CONFLITO DE INTERPRETAÇÃO ENTRE A JURISDIÇÃO DA Corte Interamericana de Direitos Humanos e o Supremo Tribunal Federal quanto a LEI DE ANISTIA 612

Carla Ribeiro Volpini Silva e Bruno Wanderley Junior

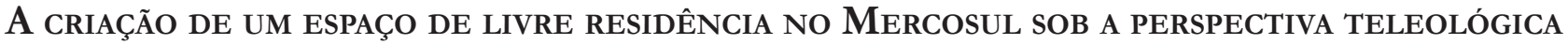
DA INTEGRAÇÃo REGIONAL: ASPECTOS NORMATIVOS E SOCIAIS DOS ACORDOS DE RESIDÊNCIA ....... 631

Aline Beltrame de Moura

A funcionalização como tendênCia evolutiva do Direito Internacional e sua conTRIBUIÇÃO AO REGIME LEGAL DO BANCO DE DADOS DE IDENTIFICAÇÃO DE PERFIL GENÉTICO NO BRASIL

Antonio Henrique Graciano Suxberger

O DIREITO INTERNACIONAL E A PROTEÇÃO DOS DIREITOS DE CRIANÇAS E DE ADOLESCENTES EM CONFLITO COM A LEI EM MOÇAMBIQUE

Bernardo Fernando Sicoche

ObTenÇão de PRovas no EXTERIOR: PARA ALÉM dA LEX FORI E LEX DiLigENTIAE. .685 André De Carvalho Ramos 
A Slight Revenge and a Growing Hope for Mauritius and the Chagossians: The UNClos Arbitral Tribunal's Award of 18 March 2015 on Chagos Marine Protected Area (Mauritius v. United Kingdom)

Géraldine Giraudeau

ANÁLISE DA RESPONSABILIDADE INTERNACIONAL DA UCRÂNIA POR VIOLAÇÃo DOS DIREITOS HUmanos na QUeda do voo da Malaysia Airlines (MH17). .728

Daniela Copetti Cravo

NatureZa JURÍdica do DESENVOLVIMENTO SUSTENTÁVEL No DIREITO INTERNACIONAL ........739 Pedro Ivo Diniz

A INFLUÊNCIA Da SOFT LAW NA FORMaÇão do DiREITo AMBIENTAL .767 Leonardo da Rocha de Souza e Margareth Anne Leister

As COMPLICADAS INTER-RELAÇÕES ENTRE OS SISTEMAS INTERNOS E INTERNACIONAIS DE PROTEÇãO DO DIREITO AO MEIO AMBIENTE SADIO. 785 José Adércio Leite Sampaio e Beatriz Souza Costa 


\title{
Oportunidades e desafios das TWAIL no contexto latino-americano a partir de perspectivas dos povos indígenas ao direito internacional*
}

\author{
TWAIL's opportunities and challenges in \\ the latin american context from indigenous \\ peoples' perspectives to international law
}

Fernanda Cristina de Oliveira Franco **

\section{Resumo}

As TWAIL são atualmente uma das mais destacadas abordagens críticas ao direito internacional. Paradoxalmente, tornaram-se elas próprias alvo de críticas, uma das quais aponta sua frágil consideração acerca do processo de marginalização dos povos indígenas perante o direito internacional. $\mathrm{O}$ presente artigo objetiva analisar oportunidades e desafios de releituras das TWAIL no contexto latino-americano com base em perspectivas dos povos indígenas ao direito internacional. A segunda parte resgata o marco dos estudos legais (pós)coloniais para ilustrar como os povos indígenas e do Terceiro Mundo se relacionaram com o direito internacional em momentos de formação e transformação da disciplina. A terceira, expõe peculiaridades e propósitos das TWAIL e a quarta considera em que medida os povos indígenas desafiam e oportunizam releituras das TWAIL no contexto latino-americano, especialmente por se tratar da região que abriga expressiva diversidade de povos, que assumem destacado protagonismo nas instâncias de direito internacional. A Corte Interamericana é comparativamente a que oferece pronunciadas decisões sobre direitos indígenas, mas, ainda assim, é região que prossegue compactuando com ações que violentamente afetam esses povos, especialmente diante da ofensiva da exploração dos recursos naturais nos territórios tradicionais. Conclui-se que a aproximação desses elementos é teoricamente pertinente e que o desafio não é apenas o de compreender as TWAIL, mas sobretudo reinterpretá-las sob o vislumbre de que possam expressar e aprimorar o potencial transformador e de realização da justiça que se constrói na América Latina por meio das expressões indígenas.

Palavras-chave: TWAIL. Estudos legais (pós)coloniais. Direitos dos povos indígenas. Corte Interamericana de Direitos Humanos. Direito internacional na América Latina.

* Recebido em 30/10/2015.

Aprovado em 02/12/2015

** Doutoranda em Direito pelo Programa de Pós-Graduação em Ciências Jurídicas da UFPB. Mestre pelo mesmo programa. Bacharel em Direito pela Universidade de São Paulo. E-mail: ffranco.cristina@gmail.com.

\section{Abstract}

The TWAIL are currently one of the most prominent critical approaches to international law. Paradoxically, they have become themselves target 
of criticism, one of which points out its fragile consideration of indigenous people's marginalization under international law. This article aims to analyze opportunities and challenges for TWAIL's readings in the Latin American context from an indigenous peoples' perspective to international law. The second part acknowledges the (post)colonial legal studies framework to illustrate how was the relationship between indigenous and Third World peoples in moments of international law`s formation and transformation. The third exposes TWAIL's peculiarities and purposes. The fourth discusses the extent to which indigenous peoples challenge and offer opportunities for TWAIL's readings in the Latin American context, especially because it is a region that is home of a significant diversity of peoples, who take prominent role in instances of international law. The Inter-American Court is comparatively the one that offers pronounced decisions on indigenous rights, but that, even so, it is a region that continues to condone actions that violently affect indigenous peoples, especially before the threat of natural resources exploitation at traditional territories. It concludes that bringing these elements closer is a theoretically pertinent move and that the challenge is to not only understand TWAIL but rather reinterpret them under the glimpse that they can express and enhance the transformative and justice achievement potential that are built in Latin America throughout indigenous expressions.

Keywords: TWAIL. (Post)colonial legal studies. Indigenous peoples rights. Inter-American Court of Human Rights. International law in Latin America.

\section{INTRODUÇÃo}

O estudo do direito internacional tem, ao longo do tempo, se complexificado devido à multiplicidade de atores e temas com que passa a dialogar, como também em razão da profusão de vertentes teóricas e metodológicas por meio das quais passa a ser investigado ${ }^{1}$. Tais

1 No final da década de 1990 foram catalogados os seguintes métodos de direito internacional: 1) positivismo legal; 2) Escola New Haven; 3) processo legal internacional; 4) estudos críticos legais; 5) direito internacional e relações internacionais; 6) abordagem feminista do direito internacional e 7) law and economics. Conforme RATNER, Steven; SLAUGHTER, Anne-Marie. Symposium on method in international law: appraising the methods of international law: a prospectus for readers. American Journal of International Law, Washington, v. 93, n. 2, p. 291-302, 1999. análises permitem tanto reforçar leituras tradicionais do passado como também contrariar ou desconcertar interpretações estabelecidas por essas mesmas leituras. Essa última maneira de enfocar a disciplina é característica das abordagens críticas ao direito internacional, que buscam ressignificar seus principais fundamentos e doutrinas de forma a que se torne mais justo para aqueles que normalmente dele estiveram excluídos ou marginalizados ${ }^{2}$.

Uma das abordagens críticas que ultimamente tem expandido sua influência nas análises do direito internacional são as chamadas Abordagens do Terceiro Mundo ao Direito Internacional (Third World Approaches to International Law - TWAIL), cujas leituras miram a disciplina de forma provocativa a seus fundamentos clássicos, questionando suas heranças ortodoxas e, principalmente, tornando críticas as narrativas que reduziram os povos do Terceiro Mundo ${ }^{3}$ a objetos de dominação e poder. Uma de suas principais influências são os estudos (pós)coloniais ${ }^{4}$. Sob tal orientação, as TWAIL consideram em que medida as realidades coloniais e imperiais ${ }^{5}$ do direito internacional forjaram seus fundamentos, bem como de que modo suas principais doutrinas trataram de excluir e marginalizar o conhecimento e as formas organizativas dos povos não europeus domi-

2 GALINDO, George Rodrigo Bandeira. Para que serve a história do direito internacional? Revista de Direito Internacional, Brasília, v. 12, n. 1, p. 338-354, 2015. p. 343-345.

3 O termo Terceiro Mundo é atribuído originalmente a Alfred Sauvy, economista e jornalista anti-colonialista francês. Em geral, a denominação foi usada para designar um grupo de Estados "menos desenvolvidos" economicamente quando em comparação aos países do chamado Primeiro Mundo. O Segundo Mundo foi termo usado para designar os países alinhados ao bloco do regime comunista soviético da época. SAUVY, Alfred. Trois mondes, une planete. L'observateru, Paris, n. 118, p. 14, 14 aout 1952. Disponible dans: <http://www.homme-moderne.org/societe/demo/ sauvy/3mondes.html>. Accès: 06 out. 2015.

4 Nos debates iniciais sobre a terminologia adequada para nomear este campo de estudos, foram profusas as discussões e controvérsias geradas pelo uso do prefixo "pós", vez que indicaria a superação do colonialismo, constatação equivocada para muitos que alegavam a persistência das relações coloniais. Para ilustrar essa controvérsia, utiliza-se aqui o "pós" entre parêntesis. Veja KUMAR, Vidya S. A. A proleptic approach to postcolonial legal studies? a brief look at the relationship between legal theory and intellectual history. Law, Social Justice and Global Development Journal, n. 2, 2003. p. 03. Available in: <https://www2.warwick.ac.uk/fac/soc/law/elj/lgd/2003_2/ kumar>. Access: Jan. 22, 2016.

5 Para Edward Said, o colonialismo seria sempre a consequência do imperialismo, razão pela qual apresentam-se como conceitos interligados, correlatos e decorrentes. SAID, Edward W. Cultura e imperialismo. Trad. Denise Bottmann. São Paulo: Companhia das Letras, 2011. p. 42. 
nados durante a expansão colonial. Ao mesmo tempo, acabam por revelar como a participação desses povos inferiorizados no processo colonial foi fundamental em momentos de formação e transformação da disciplina.

Entretanto, ainda que as TWAIL tenham elaborado críticas cada vez mais reconhecidas pela comunidade acadêmica internacional, também têm sido elas próprias alvo de críticas, que atestam, por exemplo, não terem avançado para além da crítica, ou mesmo não terem considerado apropriadamente a posição marginal ou a situação de exclusão a que diversos grupos como mulheres, camponeses, povos indígenas e tribais foram submetidos no direito internacional ${ }^{6}$. Por essa razão, atualmente se encontram desafiadas a reformular a abrangência do conceito Terceiro Mundo para que comporte toda a diversidade e pluralidade que lhe é inerente. Particularmente, alega-se que, embora tenham discutido o problema da diferença cultural no contexto do encontro colonial, elas não articularam a noção, categoria e voz dos povos indígenas de forma satisfatória ou apropriada ${ }^{7}$.

De fato, historicamente as TWAIL construíram diálogos mais estreitos com os contextos africanos e asiáticos e apenas recentemente começam a ser discutidas por internacionalistas da região latino-americana. A América Latina, por sua vez, é a região no mundo na qual os povos indígenas representam relevante sujeito marginalizado que, apesar dos pesares, conquistou marcos de reconhecimento normativo e instâncias de participação política nas estruturas do direito internacional regional e global ${ }^{8}$. O protagonismo dos povos indígenas

6 Veja descrição sucinta das críticas às TWAIL em: CUMBERLAND, Emily. Call for Submissions for Symposium on Third World Approaches to International Law (TWAIL). Washington: American Society of International Law, March 2015. Available in: < http://www.asil. org/blogs/call-submissions-symposium-third-world-approachesinternational-law-twail>. Access: Jan. 22, 2016.

7 MUNARRIZ, Gerardo J. Rhetoric and reality: the world bank development policies, mining corporations, and indigenous communities in Latin America. International Community Law Review, v. 10, p. 431-443, 2008. p. 442.

8 Os dois instrumentos normativos globais sobre povos indígenas são a Convenção 169 da OIT e a Declaração das Nações Unidas sobre os direitos dos povos indígenas (DDPI). Dentre os órgãos das ONU dedicados à questão indígena destaque-se o Fórum Permanente das Nações Unidas sobre questões indígenas (UNPFII); A Relatoria Especial sobre os povos indígenas e o Mecanismo de Peritos. Regionalmente na OEA, há a Relatoria Regional sobre os Povos Indígenas e o sistema de petições do Sistema Interamericano de Direitos Humanos. Discute-se ainda regionalmente o texto da Declaração Americana sobre o Direito dos Povos Indígenas, com participação direta dos povos indígenas na discussão do texto. latino-americanos na construção do arcabouço normativo internacional que lhe é pertinente é reconhecido globalmente, considerando-se inclusive que esta contribuição afetou a forma como o direito internacional passou a ser aplicado aos povos indígenas do mundo todo?

Jurisdicionalmente, a Corte Interamericana de direitos humanos é órgão com decisões pronunciadas acerca dos direitos indígenas, mais do que qualquer outra Corte Internacional, o que leva à constatação de que, quando comparada a outras regiões do mundo, esta tomou a dianteira no reconhecimento legal dos direitos indígenas, pelo menos em termos normativos ${ }^{10}$. Entretanto, as violações a seus direitos prosseguem ocorrendo especialmente em razão da continuidade de um tipo contemporâneo de colonialismo extrativista ${ }^{11}$ que não encontra obstáculos para a exploração dos recursos naturais, cujas maiores reservas ainda existentes encontram-se justamente nos territórios tradicionais.

Diante dessas considerações, o presente artigo objetiva analisar oportunidades e desafios de releituras das TWAIL no contexto latino-americano considerando, para tanto, perspectivas dos povos indígenas ao direito internacional. Parte dos estudos (pós)coloniais, um dos principais marcos conceituais de influência das TWAIL, para destacar de que forma os povos colonizados participaram, ainda que, em posição marginal e excludente, em dois momentos históricos distintos de formação e transformação das principais doutrinas do direito internacional. A segunda parte do artigo aprofunda o estudo sobre as características e propósitos das TWAIL, a fim de entender com mais propriedade essa escola crítica, teórica e metodológica de direito internacional. Por fim, a terceira parte analisa em que medida o contexto latino-americano desafia e oportuniza a aproximação

9 ENGLE, Karen. The elusive promise of indigenous development: rights, culture, strategy. Durham: Duke University, 2010. p. 01.

10 Veja por exemplo, DULITZKY, Ariel E. Quando os afrodescendentes se tornaram "povos tribais": o sistema interamericano de direitos humanos e as comunidades negras rurais. Meritum, Belo Horizonte, v. 6, n. 2, p. 57-138, jul./dez. 2011. Veja também PASQUALUCCI, Jo M. International Indigenous Land Rights: a critique of the Jurisprudence of the Inter-American Court of Human Rights in light of the United Nations Declaration on the Rights of Indigenous Peoples. Wisconsin International Law Journal, v. 27, n. 01, p. 51-98, 2009.

11 Sobre as diversas tipologias do colonialismo, consulte SHOEMAKER, N. A Typology of Colonialism. Available in: <http://historians.org/publications-and-directories/perspectives-on-history/ october-2015/a-typology-of-colonialism\#.VinyWqK7OG4.facebook>. Access: Oct. 24, 2015. 
das TWAIL e povos indígenas, argumentando que essa releitura deve ir além de mera transposição das TWAIL ao contexto. Ao contrário, a tarefa é reinterpretá-las de forma a que sejam capazes de expressar e aprimorar o potencial transformador e de realização da justiça que se constrói na região por meio das expressões indígenas.

\section{INFLUÊNCIAS DOS POVOS COLONIZADOS EM MOMENTOS DE FORMAÇÃO E TRANSFORMAÇÃO DO DIREITO INTERNACIONAL}

\subsection{0 encontro entre o nativo americano e o conquistador espanhol: formação}

As análises (pós)coloniais ao direito internacional, consideradas sob o ponto de vista histórico, são relativamente recentes. Comparadas às ciências sociais em geral, a influência desses estudos no direito se deram tardiamente. Para alguns, esse envolvimento tardio seria surpreendente, visto ser impossível desconsiderar que o direito foi a frente de batalha na relação colonial. Por outro lado, apontam ser tal distanciamento compreensível, na medida em que destrinchar os aspectos da relação entre direito e (pós)colonialismo poderia inconvenientemente romper com interpretações jurídicas consolidadas ${ }^{12}$. Sob a influência de tais estudos, identifica-se que a história da relação entre direito internacional e o mundo não europeu é importante porque, por meio dela, é possível demonstrar em que medida os povos colonizados influenciaram no processo de desenvolvimento de uma série de doutrinas de direito internacional, destacando como foram criadas justamente por meio desse encontro ${ }^{13}$.

Oferecem novos parâmetros de análise à disciplina, partindo do entendimento de que há um ethos eurocêntrico que marca suas origens ${ }^{14}$. Esse ethos eurocêntrico

12 FITZPATRICK, Peter; DARIAN-SMITH, Eve. The laws of the postcolonial: an insistente introduction. In: (Eds.) Laws of the Postcolonial. Ann Arbour: University of Michigan Press, 1999. p. 1-18. p.10.

13 ANGHIE, Antony; CHIMNI, B. S. Third world approaches to international law and individual responsability in internal conflicts. Chinese Journal of International Law, v. 2, n. 1, p. 77-103, 2003. p. 84.

14 ESLAVA, Luis; PAHUJA, Sundhya. Beyond the (post)colonial: TWAIL and the everyday life of international law. Journal of Law and Politics in Africa, Asia and Latin America, v. 45, n. 2, p. 195-221, 2012. p.196. teria reforçado para que práticas, identidades e formas organizativas de sociedades não europeias permanecessem de fora dos principais fundamentos do direito internacional ${ }^{15}$. Nesse sentido, os internacionalistas que focam suas análises nas perspectivas (pós)coloniais adotam abordagem diferente da positivista, tendo como principal preocupação mostrar como o direito internacional positivista subordinou povos não europeus, bem como identificar de que forma teria sido utilizado como instrumento que legitimou a expansão do império europeu por meio do regime colonial ${ }^{16}$.

Uma das análises a que os estudos legais (pós)coloniais dão curso mostra como os nativos americanos foram, desde o momento do encontro do conquistador espanhol, excluídos do reino da soberania, destituídos, assim, do requisito fundamental para fazer parte da sociedade das nações. Por outro lado, destacam como foram eles a principal contraparte em oposição à qual o embrião do direito internacional (o jus gentium) foi gerado. Revelam, ainda, como a polarização entre o eu (o colonizador, por quem e para quem o direito internacional é feito) e o outro (os povos colonizados e excluídos do direito internacional) justificou o ímpeto de verdadeira missão civilizatória sobre o outro indígena, cujo objetivo era transformar os nativos em civilizados e cristãos, para que, a partir de então, pudessem ser integrados à comunidade das nações, à imagem e semelhança do $e$.

Curiosamente, é com atenção às considerações a respeito do outro indígena que os teólogos espanhóis da Universidade de Salamanca ${ }^{17}$, considerados por muitos internacionalistas como os precursores do direito internaciona ${ }^{18}$, estabeleceram as bases do que viria a se tornar o direito internacional. Rompendo com interpretações tradicionais, tais teólogos advogaram em defesa dos indígenas, insistindo em sua humanidade, bem

15 ANGHIE, Antony. The evolution of international law: colonial and postcolonial realities. Third World Quaterly, v. 27, n. 5, p. 739-753, 2006. p. 739.

16 ANGHIE, Antony. Finding the peripheries: sovereignty and colonialism in nineteenth-century international law. Harvard International Law Journal, v. 40, n. 1, p. 01-71, 1999. p. 01-04.

17 Dentre eles destaque-se os escritos de Bartolomé de Las Casas (1484-1566), Francisco de Vitória (1483/92-1546) e Domingo de Soto (1494-1560), que contribuíram cada qual à sua maneira e em diferentes posições políticas para construir a diferença colonial e configurar tanto os interesses dos nativos como o dos espanhóis na relação colonial.

18 KOSKENNIEMI, Martti. Empire and International Law: The Real Spanish Contribution. University of Toronto Law Journal, v. 61, p. 01-36, 2011. p. 04. 
como em seus direitos de propriedade e jurisdição. Em sua célebre lição De Indies et de Jure Belli (Os Índios e o Direito da Guerra), Francisco de Vitória argumenta que, mesmo levando em conta a suposição de que os índios fossem ineptos e rudes, mesmo assim não haveria justificativas para negar-lhes o domínio, tampouco declará-los como escravos ${ }^{19}$.

Alguns internacionalistas mais modernos ${ }^{20}$ admiraram o impulso humanitário das preleções dos teólogos espanhóis e sua propensão em discutir o império à luz do direito natural e das nações. Entretanto, acima de tudo, foram admirados por defenderem o direito dos indígenas simultaneamente ao estabelecimento de regras para o comércio espanhol e o proselitismo nos novos territórios conquistados, o que seria um caso exemplar de tomada de consciência contra os excessos causados por seu próprio país, ao mesmo tempo de expressa defesa do movimento de expansão colonial ${ }^{21}$.

Anthony Anghie, autor ligado às TWAIL, ao tecer sua crítica às lições de Vitória afirma que o teólogo não estava tão interessado no problema da ordem entre dois Estados soberanos, mas antes com o problema da criação de ordem entre duas sociedades pertencentes a dois sistemas culturais diferentes. Esta sim, a diferença cultural, teria sido crucial para a versão de soberania de Vitória, que atestou que os indígenas não seriam soberanos em razão de serem não civilizados e não cristãos ${ }^{22}$.

Dessa forma, a ausência do reconhecimento da diferença cultural precede e formata profundamente a doutrina da soberania, que, tradicionalmente, indica que uma soberania já estabelecida lide com o problema da diferença cultural internamente ${ }^{23}$. Consequentemente,

19 VITÓRIA, Francisco de. Os índios e o direito da guerra. Trad. Ciro Mioranza. Ijuí: Editora Ijuí, 2006. (Clássicos do Direito Internacional). p. 58.

20 Nomeadamente James Scott Brown. Uma das mais renomadas figuras do moderno direito internacional, James Brown Scott (18661943) publicou o livro "The Spanish Origin of International Law. Francisco De Vitoria and His Law of Nations", de 1934, sustentando que as doutrinas de Vitória são, na verdade, o primeiro trabalho a abordar o direito das nações, que viria a ser o direito internacional do mundo cristão e do mundo em geral.

21 KOSKENNIEMI, Martti. Empire and International Law: the real spanish contribution. University of Toronto Law Journal, v. 61, p. 01-36, 2011. p. 02-04.

22 ANGHIE, Antony. Francisco de Vitoria and the colonial origins of international law. Social and Legal Studies, London, v. 5, n. 3, p. 321-336, 1996. p. 332.

23 ANGHIE, Antony. The evolution of international law: colonial and postcolonial realities. Third World Quaterly, v. 27, n. 5, p. 739-753, 2006. p. 742 . as diferenças culturais foram relegadas ao âmbito interno dos Estados soberanos, ficando a ordem internacional "livre" de enfrentar tal problema. Isso afetou, profundamente, não só o direito internacional e seu inadequado tratamento à questão da diferença cultural, como também aos povos indígenas, engolidos que foram pelos Estados nacionais, ficando sujeitos e submetidos ao exercício da soberania de cada Estado-nação.

Por essa razão, Anghie atesta que a construção de Vitória, que identifica o outro como bárbaro, cria um objeto contra o qual a soberania pode expressar seu total poder, perpetrando violência não mediada, justificada como meio de conversão, salvação e civilização do nativo contra ele mesmo ${ }^{24}$. Afirma, ainda, Anghie que, decidindo-se pelo mundo colonial como não soberano, o direito internacional teria criado por si mesmo o grande projeto de trazer o mundo marginalizado ao reino da soberania, civilizando o incivilizado e desenvolvendo técnicas jurídicas e instituições necessárias para essa grande missão civilizatória. Em última análise, essa construção revelaria como o vocabulário do direito internacional, longe de ser neutro e abstrato, seria baseado na história de subordinação e marginalização de culturas nativas ${ }^{25}$.

Note-se ainda que, na história do direito internacional, tornar o outro civilizado significou torná-lo de acordo com a imagem dos europeus sobre si mesmos, revelando nesse caso o direito internacional como produto da história e da cultura europeia, incluindo os não europeus num universo de conceitos europeus ao afastar qualquer forma de identidade nativa ${ }^{26}$. Como resultado, os povos indígenas e suas formas particulares de organização ficaram de fora das principais doutrinas do direito internacional, como a da soberania ${ }^{27}$ e da nacionalida-

24 ANGHIE, Antony. Francisco de Vitoria and the colonial origins of international law. Social and Legal Studies, London, v. 5, n. 3, p. 321-336, 1996. p. 333.

25 No original, o autor usa o termo extinção de "culturas alienígenas" (alien cultures), que parece impróprio a nosso ver, pois inverte o lugar de fala, já que, do ponto de vista do nativo, do indígena, o que se extinguiu não foram as culturas alienígenas, como menciona o autor, mas sim as culturas indigenas. ANGHIE, Antony. Francisco de Vitoria and the colonial origins of international law. Social and Legal Studies, London, v. 5, n. 3, p. 321-336, 1996. p. 333.

26 KOSKENNIEMI, Martti. The gentle civilizer of nations: the rise and fall of international law 1870-1960. Cambridge: Cambridge University, 2004. p. 127-135.

27 Segundo Anghie, a doutrina da soberania consistiu em parte dos mecanismos que expulsaram sociedades não europeias do reino da soberania e poder. ANGHIE, Antony. Finding the peripheries: sovereignty and colonialism in nineteenth-century international law. 
$\mathrm{de}^{28}$, ocupando desde sempre posição marginal nas relações internacionais, cujos efeitos são sentidos até hoje.

\subsection{O encontro do direito internacional com o Terceiro Mundo: transformação}

Se o momento do encontro entre o nativo americano e o conquistador espanhol é considerado o início do período colonial, seu término é identificado com o período do pós-Segunda Guerra Mundial, momento em que antigas colônias, sobretudo na África e na Ásia, paulatinamente adquiriram autonomia política e soberania nacional, libertando-se da dominação colonial. Assim, a partir da década de 1950 e com maior ênfase nas décadas de 1960 e 1970, o direito internacional é cobrado a regular, para muito além das tradicionais questões sobre o uso da força, guerra e paz, novo e amplo universo trazido pela entrada na sociedade das nações de novos Estados oriundos do Terceiro Mundo. Revela-se um direito internacional inadaptado frente à nova realidade, que cobrava transformações para que fosse capaz de responder aos novos desafios.

Atente-se que, até então, o direito internacional havia congregado Estados europeus mais ou menos equitativos, tendo como principal intuito a preservação da 'civilização' e dos estados cristãos ${ }^{29}$. Todavia, com a entrada dos países do Terceiro Mundo na sociedade das nações, esse balanço equitativo entre os Estados foi rompido e as condições entre os membros da comunidade internacional se tornou bastante heterogênea. Assim, o direito internacional não se adequava mais como produto de determinada comunidade histórica (europeia), composto por membros com níveis comparáveis de desenvolvimento, mas ao contrário, desiguais e diversos, situação diante da qual não tinha repertório, tampouco instrumentos adequados para lidar ${ }^{30}$.

Harvard International Law Journal, v. 40, n. 1, p. 01-71, 1999. p. 741.

28 Para que o formato da nação se tornasse universal foram feitos diversos esforços, de modo a assegurar que formas não nacionais de organização política e social fossem mantidas como não universais, tanto para permitir sua dominação como para manter sua inclusão como não sujeitos de direito. Veja PAHUJA, Sandhya. The postcoloniality of international law. Harvard International Law Journal. v. 46, n. 2, p. 459-469, summer 2005. p. 463.

29 SHAW, Malcolm N. International law. 6. ed. Cambridge: Cambridge University, 2008. p. 27.

30 FLORY, Maurice. Adapting international law to the development of the Third World. Journal of African Law, v. 26, p. 12-20, 1982. p. 15.
Alegava-se que a mais importante diferença e que mais afetaria o papel do "novo" direito internacional da época seria a desigualdade entre estágios de crescimento econômico dos "velhos" e "novos" Estados, despontando o desenvolvimento como tema predominante do moderno direito internacional. Ademais, proliferaram-se métodos e canais legais que teriam como objetivo a consolidação de uma ordem legal internacional estável, sendo do interesse dos Estados mais fracos do Terceiro Mundo estabelecer tais canais legais, mais do que canais puramente políticos, uma vez que estariam claramente em larga desvantagem nesses últimos ${ }^{31}$.

Em razão dessas novas formas de resolução de conflitos, o direito internacional tornou-se alvo privilegiado de juristas do Terceiro Mundo, especialmente porque, a partir de então, as injustiças poderiam ser resolvidas no âmbito das relações e do direito internacional. Nessa esteira, ganharam impulso estudos legais de internacionalistas que passaram a advogar em defesa dos interesses dos povos do Terceiro Mundo. Delineia-se período histórico expressivo na configuração de vertente emancipatória da disciplina, já que, durante esse momento, adquire um duplo caráter, transformando gradualmente sua função de instrumental jurídico exclusivamente de regulação para um instrumental jurídico também e, sobretudo, de libertaçã $0^{32}$.

De modo geral, diversas foram as reivindicações dos países do Terceiro Mundo, contribuindo para dar densidade e novos contornos a princípios previamente existentes, como por exemplo o da autodeterminação e da soberania permanente sobre os recursos naturais, bem como lançando as bases de um novo direito: o direito ao desenvolvimento ${ }^{33}$. Ainda, pleiteando a instauração de uma nova ordem econômica internacional (NOEI) ${ }^{34}$,

31 FATOUROS, A. A. International law and the third world. Virginia Law Review, v. 50, n. 05, p. 783-823, jun. 1964. p. 791.

32 CANÇADO TRINDADE, Antônio Augusto. A bumanização do direito internacional. Belo Horizonte: Del Rey, 2006. p. 110.

33 No direito positivo, o direito ao desenvolvimento encontra-se previsto na Declaração do Direito ao Desenvolvimento. Assembleia Geral da ONU Resolução 41/128. UNITED NATIONS. Declaration on the Right to Development. 4 Dec. 1986. Available in: <http://www. un.org/documents/ga/res/41/a41r128.htm>. Access: Feb. 4, 2016. 34 A Declaração para o Estabelecimento de uma Nova Ordem Econômica Internacional (NOEI) foi adotada pela Assembleia Geral das Nações Unidas em 1974 e cobrou uma reestruturação da ordem internacional em direção a uma maior equidade para os países em desenvolvimento. Documento UNITED NATIONS. Declaration on the Establishment of a New International Economic Order. May. 1974. Available in: <http://www.un-documents.net/s6r3201.htm>. Access: Feb. 4, 2016. 
que fosse capaz de proteger a independência e soberania dos novos Estados. Sublinhe-se, contudo, não se tratar de repúdio à ordem jurídica já existente, mas sim de reivindicações por transformações situadas no interior da ordem jurídica já existente ${ }^{35}$.

Dentre diversos resultados, os novos formatos normativos reivindicados pelo Terceiro Mundo acabaram por fortalecer no direito internacional a categoria coletiva dos povos, sendo que tanto os direitos à autodeterminação, à soberania permanente sobre os recursos naturais e ao desenvolvimento firmaram-se muito mais como direito dos povos do que como direito dos Esta$\operatorname{dos}^{36}$. Nesse sentido, conforme afirma Baxi, a partir de então a reformulação do direito internacional contemporâneo não pôde mais ser entendida apenas como a história do direito das nações (law of nations) à completa exclusão do direito dos povos (law of peoples) ${ }^{37}$.

Os teóricos responsáveis por argumentos traçados desde a perspectiva dos interesses do Terceiro Mundo são considerados os precursores das Abordagens do Terceiro Mundo ao Direito Internacional (TWAIL) ${ }^{38}$. Suas análises enfatizaram que o direito internacional não era estranho aos países pré-coloniais do Terceiro Mundo, ainda que nunca tivessem tido contato prévio com o direito internacional eurocêntrico. Identificaram para isso rico corpo de doutrina e princípios nos sistemas legais e culturais de países colonizados que faziam

35 BUIRETTE-MAURAU, Patricia. La participation du Tiers-Monde a l'elaboration du droit international. Paris: Librairie Générale de Droit et de Jurisprudence, 1983. p. 19-35.

36 Para uma visão crítica a respeito do direito dos povos, veja CRAWFORD, James. The rights of peoples: 'peoples' or 'governments'? In: _ (Ed). The rights of peoples. Oxford: Oxford University, 2001. p. 55-68. p. 56. O autor problematiza a questão ao indagar se o direito internacional teria tomado para si a tarefa de conferir direito a grupos e comunidades contra os Estados que essas pessoas constituem e contra os governos destes mesmos Estados. Isso porque, para o autor, se a frase direito dos povos tiver algum significado independente, ele deve conferir direitos aos povos contra seus próprios governos, o que soaria problemático para a estrutura clássica do direito internacional.

37 BAXI, Upendra. What may the 'Third World' expect from international law? Third World Quarterly, v. 27, n. 5, p. 713-725, 2006. p. 720 .

38 Dentre os teóricos da TWAIL I, cujos trabalhos remontam à década de 1970, encontram-se por exemplo Mohammed Bedjaoui, Upendra Baxi, R.P. Anand, T.O. Elias, dentre outros. O próprio pioneiro na defesa do Direito ao Desenvolvimento como direito humano, o jurista senegalês Keba M’Baye, pode ser tido também como representante deste grupo, na medida em que, já na década de 1970 defendia, por meio da afirmação do direito internacional ao desenvolvimento, os interesses das antigas colônias africanas durante o processo de descolonização. alusão a regras de diálogo e negociações entre nações ${ }^{39}$. Constituem assim o que a doutrina nomeia de fase I das TWAIL ou TWAIL I.

\section{As ABORDAGENS DO TERCEIRO MUNDO AO DI- REITO INTERNACIONAL}

Nas últimas décadas, as escolas de direito internacional se diversificaram, surgindo, basicamente, duas grandes tendências opostas, uma delas reconhecida como corrente majoritária (mainstream) e outra cuja proposta celebra a busca por novas formas de abordar o direito internacional que não aquela tradicionalmente realizada (newstream). Essa segunda vertente, nomeada 'Novas Abordagens ao Direito Internacional' (New Approaches to International Law - NAIL), configura movimento acadêmico que surgiu oficialmente na década de 1980 com o intuito de promover perspectivas críticas, alternativas e oposicionistas ao direito internacional e sua corrente majoritária ${ }^{40}$.

As TWAIL encontraram inspiração nas NAIL, cujo objetivo é destacar bias, ideologias, controvérsias doutrinárias e conceituais presentes no direito internacional. No momento de sua origem ${ }^{41}$, o próposito das TWAIL foi discutir novas formas de pensar a relação entre o direito internacional público e o direito econômico internacional, bem como sobre questões de riqueza e pobreza. Além disso, dedicaram-se a mapear abordagens anteriores do Terceiro Mundo ao direito internacional, com vistas a entender em que medida as críticas, por exemplo, ao formalismo e à soberania que estavam em ascensão nos países desenvolvidos seriam ou não igualmente relevantes para os países do Terceiro Mundo. Ainda, preocuparam-se em analisar como a história

39 ANGHIE, Antony; CHIMNI, B.S. Third world approaches to international law and individual responsability in internal conflicts. Chinese Journal of International Law, v. 2, n. 1, p. 77-103, 2003. p. 80-81. 40 O trabalho seminal das NAIL é atribuído a David Kennedy, especialmente por meio da obra KENNEDY, David. International legal structures. Baden-Baden: Nomos, 1987. Bem como, posteriormente, pela obra de KOSKENNIEMI, Martti. From apology to utopia: the structure of international legal argument . Cambridge: Cambridge University, 1989. As NAIL são retomadas no trabalho de KENNEDY, David. When renewal repeats: thinking against the box. York Journal of International Law and Politics, v. 32, n. 2, p. 335500, Winter 2000.

41 O surgimento oficial das TWAIL situa-se no momento da realização da Conferência "New Approaches to Third World Legal Studies" (1997). 
do direito internacional era contada e, dessa forma, re-examinar seus fundamentos históricos ${ }^{42}$.

Desde então as TWAIL têm se firmado como escola de pensamento, como método de direito internacio$\mathrm{nal}^{43}$, como comunidade intelectual e epistêmica, como movimento acadêmico ${ }^{44}$, como abordagem peculiar ao direito internacional ${ }^{45}$, dentre várias outras denominações que mostram a diversidade de abordagens que lhe dá nome.

\subsection{Relação com outras abordagens críticas ao direito internacional}

As abordagens críticas ao direito internacional são aquelas que buscam iluminar pontos até então obscuros ou pouco abordados pela mainstream positivista e liberal ${ }^{46}$. O interessante das teorias críticas é que geram conflito e estimulam o debate, na medida em que descrevem um mesmo objeto (direito internacional) por ângulos opostos e múltiplos, revelando face excludente e de dominação, ainda que sem desacreditar, pelo contrário, na renovação do direito internacional que seja condizente com a promessa de proteção do pluralismo na vida internacional $l^{47}$.

42 GATHII, James Thuo. TWAIL: A brief history of its origins, its decentralized network, and a tentative bibliography. Trade Law and Development, v. 3, n. 1, p. 27-64, 2011. p. 29-30.

43 OKAFOR, Obiora C. Critical third world approaches to international law (TWAIL): theory, methodology, or both? International Community Law Review, v. 10, p. 371-378, 2008. p. 378.

44 PARMAR, Pooja. TWAIL: an epistemological inquiry. International Community Law Review, v. 10, p. 363-370, 2008. p. 364.

45 ANGHIE, Antony; CHIMNI, B. S. Third world approaches to international law and individual responsability in internal conflicts. Chinese Journal of International Law, v. 2, n. 1, p. 77-103, 2003. p. 102.

46 Chimi lista dentre elas as abordagens: (i) realista - cuja maior influência vem de Hans Morgenthau, prevê que o rule of law internacional é submetido à política internacional, baseada em relações de poder; (ii) liberal - defendem que o direito internacional assume papel fundamental na manutenção da ordem na sociedade internacional e que facilita uma resposta colaborativa para problemas chave da sociedade internacional; (iii) crítica - identifica vários problemas nas abordagens realista e liberal; e (iv) feminista - incorporou muitos insights da abordagem crítica desafiando o direito internacional a partir de uma perspectiva de gênero e (v) abordagem do Terceiro Mundo - que guarda afinidades com as perspectivas críticas e feministas. CHIMNI, B. S. Legitimating the international rule of law. In: CRAWFORD, J.; KOSKENNIEMI, M. (Ed.). The Cambridge companion to international law. Cambridge University, 2012. p. 290-308. p. 295-300.

47 MÉGRET, Frédéric. International law as law. In: CRAWFORD, J.; KOSKENNIEMI, M. (Ed.). The Cambridge companion to international law. Cambridge University, 2012. p. 64-92. p. 81.
De acordo com Chimni, as TWAIL guardam relações mais estreitas com as perspectivas crítica e feminis$\mathrm{ta}^{48}$. Embora se reconheça que as três sejam genericamente abordagens críticas ao direito internacional, cada qual configura universo particular e parte de premissas próprias. Consideradas as diferenças, o que as une é que compartilham o entendimento do direito internacional não como elemento neutro ou acima das relações de poder, mas ao contrário, como política e culturalmente originado e orientado.

Com a abordagem feminista, compartilham entendimentos comuns, por exemplo, em relação ao fato de ambas entenderem que o direito internacional se consolidou com base em conceitos, vocabulários e instituições problemáticas aos grupos subalternos ${ }^{49}$, sejam eles mulheres ou povos dos países do Terceiro Mundo. Por outro lado, as TWAIL divergem das perspectivas feministas por entenderem que elas não apreciaram, suficientemente, a íntima relação entre capitalismo, imperialismo e direito internacional ${ }^{50}$.

Provavelmente, a maior crítica às TWAIL seja justamente ao fato de que focam sua análise na crítica, sem elevar o nível das respostas e propostas em alternativa ao que criticam ${ }^{51}$. Defensores das TWAIL alegam, todavia, que elas não buscam apenas criticar, mas também oferecer possibilidades para o futuro do direito internacional, tendendo a imaginar e predizer as formas pelas quais o direito internacional se comportaria frente ao Terceiro Mundo, ou parte dele, no longo prazo ${ }^{52}$.

48 CHIMNI, B. S. Legitimating the international rule of law. In: CRAWFORD, J.; KOSKENNIEMI, M. (Ed.). The Cambridge companion to international law. Cambridge University, 2012. p. 290-308. p. 299. 49 O conceito de subalterno foi cunhado pelo italiano Gramsci e se refere a uma pessoa ou grupo em situação de inferioridade e excluída da hegemonia do poder. Tal conceito foi resgatado pelo grupo de estudos (pós)coloniais conhecido como Subaltern Studies, cujas reflexões tiveram como primeiro objetivo produzir análises históricas nas quais os grupos subalternos fossem vistos como sujeitos da história e não apenas como objetos de dominação. LUDDEN, David (Org). Reading subaltern studies: critical history, contested meaning and the globalization of South Asia. London: Anthem, 2002. p. 15.

50 CHIMNI, B. S. Legitimating the international rule of law. In: CRAWFORD, J.; KOSKENNIEMI, M. (Ed.). The Cambridge companion to international law. Cambridge University, 2012. p. 290-308. p. 299. 51 GORDON, Seth. Indigenous rights in modern international law from a critical third world perspective. American Indian Law Review, v. 31, p. 401-424, 2006. p. 413.

52 OKAFOR, Obiora C. Critical third world approaches to international law (TWAIL): theory, methodology, or both? International Community Law Review, v. 10, p. 371-378, 2008. p. 373. 
Em suma, alega-se que as TWAIL destacaram, com sucesso, relações coloniais e imperiais que monopolizaram a elaboração e destinação do direito internacional sem, entretanto, terem conseguido até agora oferecer agenda positiva para reformar ou transformar o direito internacional com vistas a efetivar a realização dos propósitos aos quais almejam.

\subsection{Propósitos das TWAIL}

As TWAIL se caracterizam mais pelas diferenças internas e diversidade de pontos abordados do que por unidade de discurso e propósitos. Ainda assim, guardam entre si elementos de coerência e unidade, expressos em ideais mais ou menos comuns. De forma geral, dedicam-se a tornar possível a construção de um direito internacional sob a perspectiva daqueles que normalmente ficaram de fora da construção desse direito. Com isso, propõe repensar os modos tradicionais de ler e escrever o direito internacional, bem como sintonizá-lo a lugares e sujeitos alijados do processo de sua construção ${ }^{53}$.

Uma das formas por meio das quais se valem para construir suas análises é considerar não apenas as perspectivas dos Estados (como os realistas e positivistas fazem) ou dos indivíduos (como os liberais e naturalistas fazem), mas especialmente dos povos, normalmente identificados com os povos do 'Terceiro Mundo"54, já que defendem que para as TWAIL o direito internacional faz sentido apenas no contexto da história viva desses povos ${ }^{55}$. Isso quer dizer que o cotidiano dos povos marginalizados do Terceiro Mundo é foco comum e o intuito é desvendar os conhecimentos julgados como hierarquicamente inferiores que radicam justamente na experiência por eles vivida.

Advém daí forma particular de aprender com a vida das pessoas e privilegiar conhecimentos locais, validando o engajamento com os interesses, preocupações, histórias e lutas que foram relegadas às margens do direito internacional como consequência do colonialismo e do

53 ESLAVA, Luis; PAHUJA, Sundhya. Beyond the (post)colonial: TWAIL and the everyday life of international law. Journal of Law and Politics in Africa, Asia and Latin America, v. 45, n. 2, p. 195-221, 2012. p. 02.

54 RAJAGOPAL, Balakrishnan. International law and social movements: challenge of theorizing resistance. Columbia Journal of Transnational Law. v. 41, n. 2, p. 396-433, 2003. p. 401.

55 ANGHIE, Antony; CHIMNI, B. S. Third world approaches to international law and individual responsability in internal conflicts. Chinese Journal of International Law, v. 2, n. 1, p. 77-103, 2003. p. 78. imperialismo ${ }^{56}$. Nesse sentido, a intenção desses estudiosos é contribuir com a construção de um tipo de saber que amplie os limites do pensamento ocidental, agregando outros conhecimentos, com vistas à construção de um direito internacional verdadeiramente universal, ou melhor, pluriversal ${ }^{57}$, que crie condições de diálogo e convivência entre os múltiplos e interconectados povos que se relacionam sob a égide da sociedade global, superando de vez as heranças coloniais que marcaram as relações entre eles.

\subsection{Que Terceiro Mundo?}

Muito se indaga a respeito da pertinência do uso da terminologia 'Terceiro Mundo' em épocas contemporâneas, uma vez que a composição política do contexto da Guerra Fria que lhe deu origem já não mais subsiste. $\mathrm{Na}$ esteira crítica do termo, surgem proposições que celebram construções de uma humanidade comum a todos os povos da terra - expressão nomeada por Baxi de 'um-mundismo ${ }^{58}$. Adverte o professor indiano que para as proposições baseadas no 'um-mundismo', o fenômeno 'Terceiro Mundo' de fato ou nunca existiu, ou então é apenas uma categoria que congrega massivas histórias de desapontamentos e fracassos descoloniais.

Todavia, mesmo diante do fato de ser considerada categoria 'fora de moda' para diversos círculos intelectuais, os estudiosos ligados às TWAIL insistem no seu uso, sustentando ser importante para uma releitura do direito internacional em termos de maior justiça e inclusã ${ }^{59}$. Assim, afirmam que a categoria Terceiro Mundo continua a ser relevante, sobretudo em razão do potencial que tem para revelar a ordem hierárquica da comunidade internacional. Permite identificar e localizar suas

56 PARMAR, Pooja. TWAIL: an epistemological inquiry. International Community Law Review, v. 10, p. 363-370, 2008. p. 365.

57 RAJAGOPAL, Balakrishnan. Postdevelopment as a vision for a third world approach to international law. In: ANNUAL MEETING AMERICAN SOCIETY OF INTERNATIONAL LAW, 94. Washington, 2000. Proceedings...Washington: ASIL, 2000. p. 306-307. p. 307. Veja também: CHIMNI, B. S. Legitimating the international rule of law. In: CRAWFORD, J.; KOSKENNIEMI, M. (Ed.). The Cambridge companion to international law. Cambridge: Cambridge University, 2012. p. 290-308.

58 BAXI, Upendra. What may the 'Third World' expect from international law? Third World Quarterly, v. 27, n. 5, p. 713-725, 2006. p. 714 .

59 GALINDO, George Rodrigo Bandeira. A volta do terceiro mundo ao direito internacional. Boletim da Sociedade Brasileira de Direito Internacional, v.1, n. 119-124, p. 46-68, ago./dez. 2013. p. 46. 
raízes histórico-culturais na experiência do colonialismo e do imperialismo, duas dimensões que não são totalmente capturadas quando se adota outros termos como por exemplo "em desenvolvimento", ou "Sul Global"

Em síntese, a opção das TWAIL pela continuidade no uso do 'Terceiro Mundo' procura desvincular o termo do tradicional contexto de nações que pertencem a um grupo de países economicamente periféricos e atrasados para reeditá-lo como expressão de contraponto e resistência à ordem internacional hegemônica (e injusta) sobre o globo ${ }^{61}$.

\section{Povos Indígenas e TwaIL: DIÁlogos a PAR- TIR DO CONTEXTO LATINO-AMERICANO}

\subsection{A presença dos povos indígenas na América Latina e no direito internacional dos direitos humanos}

Estima-se que os povos indígenas representem 370 milhões de pessoas presentes em cerca de 90 países de todos os continentes. Constituem 5 por cento da população mundial, mas representam 15 por cento dos pobres do mundo, o que demonstra como são desproporcionalmente afetados quando comparados à população não indígena ${ }^{62}$. A América Latina é região particularmente rica e diversa em termos de presença de povos indígenas. Calcula-se que sejam em torno de 800 povos, com uma população próxima de 45 milhões de pessoas, que se caracterizam por sua ampla diversidade demográfica, social, territorial e política, que vive desde situações de isolamento voluntário até grandes assentamentos urbanos ${ }^{63}$.

60 RAJAGOPAL, Balakrishnan. Locating the Third World in Cultural Geography. Third World Legal Studies, v. 15, n. 2, p. 01-20, 1999. p. 03.

61 MUTUA, Makau. What it TWAIL? In: ANNUAL MEETING AMERICAN SOCIETY OF INTERNATIONAL LAW, 94. Washington, 2000. Proceedings...Washington: ASIL, 2000. p. 31-39. p. 35-36.

62 Fórum Permanente das Nações Unidas sobre Questões Indígenas: State of Indigenous Peoples. UNITED NATIONS. State of the worlds indigenous peoples. New York: United Nations, 2009. Available in: <http://issuu.com/uniccanberra/docs/state_of_world_s_indigenous_peoples/1>. Access: Oct. 05, 2015.

63 COMISSÃO ECONÔMICA PARA A AMÉRICA LATINA E O CARIBE. Os povos indígenas na América Latina: avanços na última década e desafios pendentes para a garantia de seus direitos. Nações
Como sujeitos de direito internacional, seu reconhecimento é relativamente recente. As primeiras movimentações nesse caminho datam da década de 1970, quando organizações indígenas nacionais começaram a ganhar densidade política em vários países, incluindo Canadá, Estados Unidos, Austrália e diversos países da América Latina ${ }^{64}$. Os resultados dessa intensa luta por reconhecimento ficaram evidentes nas últimas décadas, quando efetivamente emergiram como sujeitos no regime do direito internacional dos direitos humanos. Vencendo inúmeros obstáculos, o fato é que os direitos dos indígenas se tornaram parte relativamente ampla e permanente da agenda intergovernamental de direitos humanos nas últimas décadas. O padrão internacional se fortaleceu consideravelmente, resultando: (i) em instrumentos de direitos humanos especificamente direcionados à regulamentação dos direitos dos povos indígenas (Convenção 169 da OIT sobre Povos Indígenas e Tribais (1989), Declaração da ONU sobre os Direitos dos Povos Indígenas (2007), Projeto de Declaração Americana sobre os Direitos dos Povos Indígenas); (ii) na incorporação de alguns desses direitos em instrumentos outros de direitos humanos (Convenção sobre a Diversidade Biológica (1992), Convenção sobre a proteção e promoção da diversidade das expressões culturais (2005)); (iii) na interpretação da possibilidade de proteção dos direitos indígenas sob instrumentos de direitos humanos de aplicação geral (Declaração Universal dos Direitos Humanos (1948), Convenção Americana de Direitos Humanos (1969), Pacto Internacional de Direitos Econômicos, Sociais e Culturais (1966)).

Vale destacar que não há uma definição fixa adotada internacionalmente sobre o significado do termo 'povos indígenas', havendo várias definições e discussões sobre como deve ser entendido. A principal polêmica e o motivo de contestações por parte dos Estados se deram em razão do significado específico que o termo povos adquire no direito internacional ao atribuir-lhes direito à autodeterminação ${ }^{65}$. A Convenção 169 da OIT tratou,

Unidas: Santiago do Chile, 2015. p. 06.

64 ENGLE, Karen. The elusive promise of indigenous development: rights, culture, strategy. Durham: Duke University, 2010. p. 17.

65 O status de povo teoricamente lhes garante o direito à autodeterminação, conforme o artigo 1 (1) do Pacto Internacional dos Direitos Civis e Políticos e dos Econômicos, Sociais e culturais, ambos com igual redação. BRASIL. Decreto no 592, de 6 de julho de 1992. Atos Internacionais. Pacto Internacional sobre Direitos Civis e Políticos. Promulgação. Disponível em: <http://www.planalto.gov.br/ccivil_03/decreto/1990-1994/D0592.htm>. Acesso em: 20 out 2015. 
assim, de limitar esse entendimento, assegurando que a utilização do termo "povos" pelo documento não seria interpretada no sentido de ter implicação alguma aos direitos que poderiam ser conferidos a esse termo no direito internacional ${ }^{66}$. Já a DDPI foi mais abrangente $\mathrm{e}$ finalmente reconheceu o direito dos povos indígenas à autodeterminação ${ }^{67}$.

Por sua vez, o termo indigena se refere amplamente aos descendentes vivos dos habitantes da terra no período pré-invasão europeia e que hoje são dominados por outros, constituindo povos, nações ou comunidades culturalmente distintas, que foram engolidas pelas sociedades coloniais nascidas das forças do império e da conquista $^{68}$. De acordo com a Convenção 169 da OIT, os povos indígenas são aqueles assim considerados pelo fato de descenderem de populações que habitavam região pertencente ao país na época da conquista ou da colonização e que conservam suas próprias instituições sociais, econômicas, culturais e políticas, ou parte de$\operatorname{las}^{69}$.

Contudo, por abranger uma série de características não exaustivas, não existe uma definição amplamente aceita acerca do que venha a ser indígena, razão pela qual o direito internacional e as Nações Unidas corroboram, jurídica e politicamente, a moderna tendência de tomar a ideia sobre quem é ou não indígena com base no princípio da autoidentificação. Assim, a Convenção assegura que a consciência da identidade indígena ou tribal será considerada como critério fundamental para determinar os grupos aos que se aplicam as disposições do documento $^{70}$.

66 Redação conforme artigo 01 (3) da DDPI. NAÇÕES UNIDAS. Declaração das Naçoes Unidas sobre os Direitos dos Povos Indígenas. Rio de Janeiro, 2008. Disponível em: <http://www.un.org/esa/ socdev/unpfii/documents/DRIPS_pt.pdf $>$. Acesso em: 20 out 2015.

67 NAÇÕES UNIDAS. Declaração das Nações Unidas sobre os Direitos dos Povos Indígenas. Rio de Janeiro, 2008. Disponível em: <http:// www.un.org/esa/socdev/unpfii/documents/DRIPS_pt.pdf $>$. Acesso em: 20 out. 2015.

68 ANAYA. S. J. International human rights and indigenous peoples: the move toward the multicultural state. Arizona Journal of International and Comparative Law, v. 21. n. 1, p. 15-61, 2004. p. 3.

69 Redação conforme artigo 1 (b). Disponível em: BRASIL. Decreto no 5051, de 19 de abril de 2004. Promulga a Convenção no 169 da Organização Internacional do Trabalho - OIT sobre Povos Indígenas e Tribais. Disponível em: <http://www.planalto.gov.br/ ccivil_03/_ato2004-2006/2004/decreto/d5051.htm>. Acesso em: 20 out. 2015.

70 De acordo com o artigo 2 da Convenção 169 da OIT. BRASIL. Decreto no 5051, de 19 de abril de 2004. Promulga a Convenção no 169 da Organização Internacional do Trabalho - OIT sobre Povos
Normativamente, há uma multiplicidade de estruturas possíveis para a reivindicação dos direitos dos povos indígenas ${ }^{71}$, diante da qual alguns autores discutem se o arcabouço dos direitos humanos e o padrão trazido por ele bastaria de forma satisfatória para contemplar os complexos problemas que enfrentam ou se, ao contrário, novas categorias legais seriam necessárias ${ }^{72}$. Independentemente da discussão, o fato é que a grande maioria das reivindicações atuais sobre a questão em âmbito internacional são delineadas com base no regime dos direitos humanos. Nesse sentido, é que Anne Orford constata atuarem os direitos humanos como canais por onde o direito internacional consegue encontrar aberturas de mediação com outros tipos de direito $^{73}$. Essa maior abertura dos direitos humanos implica inegavelmente na confrontação de valores, sentidos e significados contidos na tradicional/original doutrina dos direitos humanos com os novos valores, sentidos e significados que chegam por meio da abertura ao diálogo com outras culturas. Os povos indígenas são um dos exemplos desses outros que, ao serem alcançados pelos direitos humanos, não só sofrem a transformação de traduzirem suas visões para a linguagem jurídica, como também influenciam na elaboração desta linguagem jurídica que busca alcançá-los. Prosseguem nesse formato de forma controversa, especialmente em razão da insuficiência do sistema em implementar e assegurar direitos a esses grupos ${ }^{74}$.

A Corte Interamericana de Direitos Humanos tem sido órgão jurisdicional dedicado a analisar casos envolvendo violações de direitos indígenas, peticionados especialmente

Indígenas e Tribais. Disponível em: < http://www.planalto.gov.br/ ccivil_03/_ato2004-2006/2004/decreto/d5051.htm>. Acesso em: 20 out. 2015.

71 São elas: (1) reivindicações baseadas em direitos humanos e não discriminação; (2) reivindicações de minorias; (3) reivindicações de autodeterminação; (4) reivindicações históricas de soberania; e (5) reivindicações sui generis como povos indígenas, incluindo aquelas baseadas em tratados ou outros acordos entre povos indígenas e estados. KINGSBURY, Benedict. Reconciling five competing conceptual structures of indigenous peoples' claims in international and comparative law. New York University Journal of International Law and Policy, v. 34, p. 189-250, 2001. p.190.

72 KINGSBURY, Benedict. Reconciling five competing conceptual structures of indigenous peoples' claims in international and comparative law. New York University Journal of International Law and Policy, v. 34, p. 189-250, 2001. p. 193.

73 ORFORD, Anne. Ritual, Mediation and the International Law of the South, Griffith Law Review, v.16, p. 353-374, 2007. p. 354.

74 MIRANDA Lillian Aponte. Indigenous peoples as international lawmakers, Journal of International Law, v. 32, n. 1, p. 203-263, 2010. p. 225. 
quando a jurisdição doméstica seja falha ou inexistente, ou então quando não há vontade política para torná-la efetiva. De maneira geral, os julgados da Corte têm, normalmente, expandido a interpretação da Convenção Americana de forma a fazer respeitar o direito dos povos indígenas a permanecer ou retornar a seus territórios tradicionais, de serem consultados apropriadamente em assuntos que lhes afetem diretamente, bem como em assegurar que exerçam suas práticas culturais, espirituais e de convivência harmônica com seus territórios e recursos naturais. Trata-se de construção jurisprudencial de destaque, já que, diferentemente de sua contraparte Africana, a Convenção Americana postulou basicamente direitos individuais sem apontar os correspondentes direitos coletivos dos $\operatorname{povos}^{75}$. Ademais, a quantidade e qualidade das decisões sobre a questão indígena prolatadas pela Corte não encontra correspondência em qualquer outra Corte Internacional ${ }^{76}$.

Observa-se, todavia, que a despeito das decisões serem consideradas paradigmáticas na expansão da jurisprudência internacional sobre os direitos dos povos indígenas, estando geralmente de acordo com os mais novos princípios trazidos pelo texto da Declaração das Nações Unidas sobre os direitos dos povos indígenas (2007), um tema em particular permanece aquém do que assegura a Declaração, qual seja, o tema do acesso aos recursos naturais. Trata-se de questão relevante que ameaça a integridade dos povos na região atualmente. Nessa área, a Corte Interamericana tem permitido aos Estados direitos residuais no acesso e exploração desses recursos em detrimento dos direitos dos povos indígenas $^{77}$. Normalmente resultam dessa omissão ou permis-

75 PASQUALUCCI, Jo M. The evolution of international indigenous rights in the inter-american human rights system. Human Rights Law Review, v. 6, n. 2, p. 281-322, 2006. p. 283.

76 Os casos analisados pela Comissão Interamericana sobre os povos indígenas também são diversos. Aqui está se referindo apenas aos casos julgados (sentença de mérito) pela Corte, dentre os quais é possível mencionar: Caso Yakye Axa Indigenous communities vs. Paraguay (junho/2015); Caso Indigenous Communities Kuna of Madungandí e Emberá de Bayano e seus membros vs. Panama (outubro/2014); Caso Norín Catrimán et al. (Mapuche Indigenous People) vs. Chile (maio/2014); Caso Kichwa Indigenous People of Sarayaku vs. Ecuador (junho/2012); Caso Xákmok Kásek Indigenous communities vs. Paraguay (Agosto/2010); Caso Sawhoyamaxa Indigenous Community vs. Paraguay (Março/2006); Caso Mayagna (Sumo) Awas Tingni Community v. Nicaragua (Agosto/2001). Essa lista aumenta quando inclui petições dos povos tribais, que se apropriam e beneficiam do mesmo arcabouço criado para os povos indígenas, a exemplo do Caso Saramaka People vs. Suriname (Novembro/2007).

77 PASQUALUCCI, Jo M. International Indigenous Land Rights: a critique of the Jurisprudence of the Inter-American Court of Hu- sividade ofensivas aos territórios tradicionais de atores não indígenas responsáveis por empreender ações de exploração dos recursos naturais, cujos efeitos colaterais são extremante danosos para a sobrevivência física e cultural desses povos. Nessa área, a Corte tem sido acusada de apresentar apenas uma defesa retórica aos $\operatorname{povos}^{78}$.

\subsection{Disputas por recursos naturais: a violência sobre os povos indígenas na região latino-ame- ricana}

De fato, a despeito das proteções trazidas pelo regime dos direitos humanos, presencia-se uma cena internacional marcada por diversos conflitos envolvendo povos indígenas e ofensivas que os ameaçam constantemente. Na América Latina, os conflitos se dão expressivamente em virtude das disputas pelos recursos naturais abundantes tanto na região como nos territórios indígenas, locais que normalmente representam a última fronteira de exploração das indústrias extrativas e de geração de energia.

O conflito intensifica-se em razão da disputa — simbólica, cultural, axiológica, teleológica - pelo uso dos recursos naturais, vez que, se por um lado as indústrias os enxergam como 'recurso', como matéria prima para a geração de seu "produto" mercadológico, os povos indígenas veem esses mesmos elementos como fonte de sua sobrevivência física, social, cultural e espiritual. Entram em colisão com a visão indígena processos de exploração econômica que coisificam a natureza como 'recurso natural' e os contabiliza como insumo da produção econômica ${ }^{79}$. Estabelece-se o conflito entre a le-

man Rights in light of the United Nations Declaration on the Rights of Indigenous Peoples. Wisconsin International Law Journal, v. 27, n. 01, p. 51-98, 2009. p. 54.

78 ANTKOWIAK, Thomas M. Rights, resources, and rhetoric: indigenous peoples and the Inter-American Court. University of Pennsylvania. Journal of International Law, v. 35, n. 1, p. 113-187, 2014. p. 187.

79 Os exemplos de conflitos com a participação dos Estados nacionais com a presença de corporações transnacionais são inúmeros e ocorrem na maior parte dos países da América Latina. Cite-se apenas para ilustrar alguns casos de construção de Hidrelétricas: Hidroaysen na Patagônia Chilena; Chan-75, no Panamá; La Parota, no México, Belo Monte, no Brasil. Destaque-se as intensas atividades mineradoras de corporações Canadenses e Chinesas no Peru; o gasoduto entre os Bolívia-Brasil que destruiu vastas áreas do território dos Chiquitanos; no Equador, conflitos sobre a exploração de petróleo em território do Shuar e dos Sarayaku, dentre outros casos abundantes na literatura. 
gitimidade de atuação do Estado como agente de desenvolvimento e o direito dos povos indígenas de terem direito às suas terras, territórios e recursos naturais que possuem e ocupam tradicionalmente ${ }^{80}$. $\mathrm{Na}$ base do uso e regulação dos recursos, está o direito internacional, arena da luta entre o imperativo da exploração dos recursos e da proteção dos direitos humanos dos povos indígenas.

Nesse ponto, vale abrir um parêntesis para mencionar que um dos propósitos das TWAIL é justamente revelar inconsistências e unilateralidades do direito internacional, dedicando-se a enfrentar o tema das contradições internas ao buscar as origens das discrepâncias entre linguagens utilizadas nos diferentes ramos ou regimes internacionais como, por exemplo, o fato de o direito internacional se dedicar à regulamentação e promoção dos direitos humanos, mas, por outro lado, destinar pouca atenção quando a prática do comércio internacional ou das ações de desenvolvimento econômico consistentemente violam aqueles direitos ${ }^{81}$.

Destaque-se que as ações de exploração de recursos naturais a que se faz menção são normalmente expressas em termos de desenvolvimento nacional e envolvem íntima colaboração do Estado às ações das corporações, contrariando compromissos legais internacionalmente assumidos de proteção aos direitos territoriais dos povos indígenas $^{82}$. Revelam a violência estrutural a que esses povos estão submetidos no contexto do desenvolvimento global, cujos impactos negativos tornam mais grave seu quadro histórico de vulnerabilidade e marginalização ${ }^{83}$. A séria devastação e abusos causados

80 Conforme artigo 26 (1) da DDPI. NAÇÕES UNIDAS. Declaração das Nações Unidas sobre os Direitos dos Povos Indígenas. Rio de Janeiro, 2008. Disponível em: <http://www.un.org/esa/socdev/ unpfii/documents/DRIPS_pt.pdf $>$. Acesso em: 20 out. 2015.

81 BADARU, Opeoluwa A. Examining the utility of third world approaches to international law for international human rights law. International Community Law Review, v. 10, p. 379-387, 2008. p. 383.

82 Sobre a ação das corporações em territórios indígenas e sua responsabilização perante o direito internacional veja: MIRANDA, Lillian Aponte. The hybrid state-corporate enterprise and violations of indigenous land rights: theorizing corporate responsibility and accountability under international law. Lewis e Clark. Law Review, v. 11, n. 01 , p. $135-183,2007$. p. 147.

83 Sobre o impacto dos grandes projetos de desenvolvimento sobre os povos indígenas veja: Relatório do Relator Especial sobre a situação dos direitos humanos e liberdades fundamentais dos povos indígenas, Rodolfo Stavenhagen, E/CN.4/2003/90 21, Janeiro, 2003. STAVENHAGEN, Rodolfo. Relatório sobre a situação dos direitos bumanos e liberdades fundamentais dos povos indigenas. 2003. Disponível em: <http://www.unhchr.ch/huridocda/huridoca.nsf/e06a5300f9 0fa0238025668700518ca4/30f0fcfc1eb1b247c1256d09003152b2/\$ na região por projetos de danosos impactos refletem a continuidade de uma relação colonial e de exploração dos territórios dos povos indígenas, que permanecem excluídos dos centros de regulação dessa dinâmica ${ }^{84}$.

Na prática, mesmo diante do reconhecimento como sujeitos de direitos humanos, continuam sendo violentados sistematicamente, situação diante da qual é possível dizer que os povos indígenas sofrem duplamente o impacto das práticas coloniais, pois, além de sofrerem o processo colonial externo, também sofrem os efeitos de um tipo de colonialismo interno, que na maior parte das legislações nacionais os submete a um regime da tutela estatal. Esse tipo interno é ainda ocasionado em razão de ações ou omissões dos governos dos Estados nacionais dentro dos quais estão inseridos e da percepção das sociedades nacionais que os acusa de representarem impedimentos à livre circulação do capital e ao projeto de "modernidade" que está por detrás dos grandes empreendimentos. Alega-se que vivem outro tempo, algo como pré-capital, realidade que pertence ao pré-moderno e assim são vistos como oriundos de um tempo passado, rotulados de arcaicos e atrasados, parte de uma forma de vida a ser superada ${ }^{85}$.

Curiosamente, embora essas evidências possam ser perfeitamente trazidas à tona por meio das ferramentas analíticas oferecidas pelas TWAIL, e mesmo diante de serem os povos indígenas importantes protagonistas de ações de resistência contra uma ordem internacional injusta, as TWAIL pouco ou quase nada disseram sobre eles. Essa débil consideração é apontada atualmente como uma lacuna a ser enfrentada por estas abordagens.

\subsection{O lugar dos povos indígenas nas TWAIL: es- treitando o diálogo}

A razão do frágil diálogo entre as TWAIL e os povos indígenas pode ser investigada sob algumas hipóteses. Uma das linhas de investigação pode se orientar pelo fato de as TWAIL, por terem sofrido influências das análises marxistas (binárias) de classe, não terem apro-

FILE/G0310544.pdf>. Acesso em: 14 out. 2015.

84 MUNARRIZ, Gerardo J. Rhetoric and reality: the world bank development policies, mining corporations, and indigenous communities in Latin America. International Community Law Review, v. 10, p. 431-443, 2008. p. 431; 442.

85 As palavras são de Chaterjee, a respeito dos povos colonizados, mas perfeitamente aplicáveis ao contexto dos povos indígenas. CHATTERJEE, Partha. Colonialismo, modernidade e política. Trad. Fábio Figueiredo. Salvador: EDUFBA, 2004. p. 71. 
priadamente elaborado categorias capazes de lidar com pluralidades como gênero, raça e etnia ${ }^{86}$. Outra razão pode ser devida ao tênue diálogo das TWAIL no contexto latino-americano, região rica, diversa e combativa em termos de presença e atuação dos povos indígenas.

Argumenta-se não ser essa aproximação em desacordo com os propósitos das TWAIL, pois, se de fato se declaram como contraponto que exerce o direito internacional a partir de sua face emancipatória ${ }^{87}$, como abordagem dirigida principalmente a moldar a lei internacional favoravelmente aos que foram tradicionalmente excluídos e marginalizados por ela, como preocupadas em escavar os conhecimentos subordinados ${ }^{88}$, então seguramente desempenham papel importante na projeção das vozes e visões dos povos indígenas no direito internacional.

Mas de que forma a categoria 'Terceiro Mundo' poderia entrar em diálogo com os povos indígenas, se estes nunca se identificaram nesses termos? Como os povos indígenas podem se identificar com a ideia de Terceiro Mundo se resta incerta e obscura sua participação nesse universo? Gordon opina que ainda que os povos indígenas possam não se identificar com o sentido do senso comum sobre o Terceiro Mundo, certamente eles se encaixam na situação de, assim como os povos do Terceiro Mundo, também terem sido eles vitimizados em razão do processo colonial.

Dessa forma, segundo o autor, desde que o Terceiro Mundo e os povos indígenas compartilhem características comuns, como por exemplo, de terem sido sujeitos à dominação por um sistema legal internacional que os destituiu de poder, as ferramentas oferecidas pelas TWAI podem entrar em diálogo com a realidade dos povos indígenas, na tentativa de explicar a situação indígena perante o direito internacional e em identificar como o atual sistema falhou e provavelmente continue

86 Na opinião de Singh, as omissões das histórias dos povos tribais seriam reflexo de certa insensibilidade do teórico indiano B. S. Chimni, que mais bem conceitualizou as TWAIL no contexto indiano. Veja: SINGH, Prabhakar. Indian International law: from a colonized apologist to a subaltern protagonist. Leiden Journal of International Law, v. 23, p. 79-103, 2010. p. 95. Chimni dedicou-see análises marxistas de direito internacional, conforme. CHIMNI, B. S. Marxism and international law: a contemporary analysis. Economic and Political Weekly, v. 34, n. 6, p. 337-349, Fev. 6-12, 1999.

87 CHIMNI, B. S. The past, present and future of international law: a critical third world approach. Melbourne Journal of International Law, v. 8, n. 2, p. 499- 515, 2007. p. 500.

88 ANGHIE, Antony. LatCrit and TWAIL. California Western International Law Journal, v. 42, p. 311-319, 2012. p. 312. a falhar diante deles ${ }^{89}$. Por essa razão, entende Munarriz que as TWAIL representam valioso instrumental por meio do qual pode ser possível compreender a cumplicidade do direito internacional com a violência que foi (e ainda é) cometida contra os povos indígenas. Opina o autor que essa compreensão passa justamente pelo reconhecimento dos povos indígenas pelas TWAIL $^{90}$.

Considere-se, contudo, que, em razão da recente aproximação das TWAIL ao contexto latino-americano, ainda se elabora como de fato poderiam representar novo instrumental teórico e metodológico capaz de abordar o processo de exclusão e subalternidade a que foram submetidos os povos indígenas, bem como em que medida seriam eficazes para que as vozes e visões desses povos pudessem ser amplificadas no direito internacional, especialmente em assuntos nos quais os povos indígenas oferecem reconhecida contribuição, como é o caso de temas como desenvolvimento sustentável, biodiversidade, conhecimento tradicional, patrimônio genético e cultural, recursos naturais e mudança climática $^{91}$.

Provavelmente, um grande desafio ao se traçar as linhas desse diálogo se dê diante do fato de, conforme destaca Lorca, o direito internacional tradicionalmente não oferecer aos internacionalistas situados na periferia ferramentas analíticas adequadas para compreender o significado e usos do direito internacional em seus con-

89 GORDON, Seth. Indigenous rights in modern international law from a critical third world perspective. American Indian Law Review, v. 31, p. 401-424, 2006. p. 404.

90 MUNARRIZ, Gerardo J. Rhetoric and reality: the world bank development policies, mining corporations, and indigenous communities in Latin America. International Community Law Review, v. 10, p. 431-443, 2008. p. 435.

91 O conhecimento indígena já é considerado fundamental em domínios como a agricultura, conservação da biodiversidade, gestão dos recursos naturais, medicina tradicional e desenvolvimento sustentável. Agora, são cada vez mais reconhecidos como importante fonte de conhecimento sobre mudanças climáticas. Veja mais em: UNITED NATIONS EDUCATIONAL, SCIENTIFIC AND CULTURAL ORGANIZATION. At Geneva meeting, UNESCO affirms its commitment to indigenous peoples Rights. 2015. Available in: <http://www.unesco.org/new/en/media-services/single-view/ news/at_geneva_meeting_unesco_affirms_its_commitment_to_indigenous_peoples_rights/\#.VhVJJvlViko>. Access: Set. 01, 2015. Outro reconhecimento da importância dos povos indígenas em: Climate Change - is it the Indigenous Peoples who have the answers? Veja mais em: LUNDIN, John. Climate change: is it the indigenous peoples who have the answers? July, 2013. Available in: <http:// thedemocraticdaily.com/2013/07/27/climate-change-indigenouspeoples-answers/\#sthash.N0EZmviQ.AaXfsjOi.dpuf>. Access: Set. 01, 2015. 
textos particulares ${ }^{92}$. Por isso, deve-se considerar o risco de que quando categorias teóricas de direito internacional são transpostas para a América Latina, normalmente são reduzidas à recepção, imitação, ou na melhor das hipóteses, contribuição para o legado da disciplina ${ }^{93}$. Em se tratando das TWAIL, essa tendência pode ser revertida, especialmente porque encontram sentido exatamente na valorização do uso e significados do direito internacional exercido a partir do contexto local (a imagem do international law from below ${ }^{94}$ ), cujo sentido está radicado nas expressões dos grupos periféricos.

No contexto latino-americano, essas expressões estão bem representadas nas lutas cotidianas por reconhecimento e de resistência travadas pelos povos indígenas, inclusive por meio de canais normativos, políticos e jurisdicionais presentes na estrutura do direito internacional, especialmente os disponibilizados pelo regime internacional dos direitos humanos.

\section{Considerações finais}

As leituras críticas ao direito internacional a partir das Abordagens do Terceiro Mundo trouxeram diferentes perspectivas ao estudo da disciplina, complexificando e tornando diversas suas possibilidades de análise. Destacam não apenas o que o direito internacional contingenciou, mas também os conhecimentos por ele subjugados que, em última análise, estiveram presentes de uma forma ou de outra na construção de suas principais doutrinas. Nesse sentido, a vitalidade do discurso oferecido pelas TWAIL permite acentuar com originalidade nova concepção normativa que almeja trazer vozes e visões periféricas ao centro de produção e exercício do direito internacional a fim de torná-lo mais justo globalmente.

Provavelmente o maior desafio em relação a como considerar esses saberes subjugados e suas variadas ex-

92 LORCA, Arnulf B. International law in Latin America or latin american international law? rise, fall, and retrieval of a tradition of legal thinking and political imagination. Harvard International Law Journal, v. 47, n. 1, p. 283-305, Winter 2006. p. 283.

93 LORCA, Arnulf B. International law in Latin America or latin american international law? rise, fall, and retrieval of a tradition of legal thinking and political imagination. Harvard International Law Journal, v. 47, n. 1, p. 283-305, Winter 2006. p. 285.

94 A expressão é título do livro do professor Balakrishinan Rajagopal (2003). A reversão do mapa mundi é uma das imagens que caracteriza os estudos (pós)coloniais. pressões ocorre em razão de o direito internacional não ter vocabulário apropriado para dar conta dessa diversidade, ainda que se reconheça que, por sua essência universal, tenha todos os atributos teóricos que permitiriam esse desenvolvimento. A despeito dessas limitações, há avanços que indicam transformações nas interpretações da disciplina, principalmente no âmbito do regime jurídico internacional dos direitos humanos. Nele, os povos indígenas têm contribuído para expansões normativas e interpretativas do direito internacional que consideram suas peculiaridades como povos culturalmente distintos.

No contexto da América Latina, o uso, exercício e potencialização dos direitos dos povos ganham destaque, sendo, consequentemente, região na qual as TWAIL encontram oportunidades para enfrentar a debilidade de não terem considerado com mais propriedade a posição marginal desses grupos perante o direito internacional. Por ser uma região na qual esse assunto é exercitado de forma expressiva nas instâncias do direito internacional dos direitos humanos, encontram aí farto material vivo de investigação, capaz de lhes orientar na tarefa de superar a fragilidade em relação à consideração dos indígenas, com vistas a aprimorarem-se como contraponto emancipatório de direito internacional.

O desafio está não apenas em reproduzir ou transpor as TWAIL ao contexto latino-americano, mas, sobretudo, reinterpretá-las para que possam contribuir para refinar e amplificar o potencial transformador e de realização de justiça que se cria e exerce regionalmente com base nas expressões indígenas. Esse desafio envolve abordar o direito internacional não apenas do ponto de vista de seu próprio imaginário fundacional, mas especialmente do ponto de vista do imaginário conflitivo que surge quando, em cumprimento a seu ethos universal, alcança diferentes povos e culturas, para tornar-se, destarte, instrumental valioso no almejado diálogo entre os povos.

\section{REFERÊNCIAS}

ANAYA, S. J. International human rights and indigenous peoples: the move toward the multicultural state. Arizona Journal of International and Comparative Law, v. 21, n. 1, p. 15-61, 2004. 
ANGHIE, Antony; CHIMNI, B. S. Third world approaches to international law and individual responsability in internal conflicts. Chinese Journal of International Law, v. 2, n. 1, p. 77-103, 2003.

ANGHIE, Antony. Finding the peripheries: sovereignty and colonialism in nineteenth-century international law. Harvard International Law Journal, v. 40, n. 1, p. 01-71, 1999.

ANGHIE, Antony. Francisco de Vitoria and the colonial origins of international law. Social and Legal Studies, London, v. 5, n. 3, p. 321-336, 1996.

ANGHIE, Antony. LatCrit and TWAIL. California Western International Law Journal, v. 42, p. 311-319, 2012.

ANGHIE, Antony. The evolution of international law: colonial and postcolonial realities. Third World Quaterly, v. 27, n. 5, p. 739-753, 2006.

ANTKOWIAK, Thomas M. Rights, resources, and rhetoric: indigenous peoples and the Inter-American Court. University of Pennsylvania. Journal of International Law, v. 35, n. 1, p. 113-187, 2014.

BADARU, Opeoluwa A. Examining the utility of third world approaches to international law for international human rights law. International Community Law Review, v. 10, p. 379-387, 2008.

BAXI, Upendra. What may the 'Third World' expect from international law? Third World Quarterly, v. 27, n. 5, p. 713-725, 2006.

BRASIL. Decreto no 592, de 6 de julho de 1992. Atos Internacionais. Pacto Internacional sobre Direitos Civis e Políticos. Promulgação. Disponível em: < http://www. planalto.gov.br/ccivil_03/decreto/1990-1994/D0592. htm>. Acesso em: 20 out. 2015.

BRASIL. Decreto no 5051, de 19 de abril de 2004. Promulga a Convenção no 169 da Organização Internacional do Trabalho - OIT sobre Povos Indígenas e Tribais. Disponível em: < http://www.planalto.gov.br/ccivil_03/_ ato2004-2006/2004/decreto/d5051.htm>. Acesso em: 20 out. 2015.

BUIRETTE-MAURAU, Patricia. La participation $d u$ Tiers-Monde a l'elaboration du droit international. Paris: Librairie Générale de Droit et de Jurisprudence, 1983.

CANÇADO TRINDADE, Antônio Augusto. A humanização do direito internacional. Belo Horizonte: Del Rey, 2006.
CHATTERJEE, Partha. Colonialismo, modernidade e politica. Trad. Fábio Figueiredo. Salvador: EDUFBA, 2004.

CHIMNI, B. S. Legitimating the international rule of law. In: CRAWFORD, J.; KOSKENNIEMI, M. (Ed.). The Cambridge companion to international law. Cambridge University, 2012. p. 290-308.

CHIMNI, B. S. Marxism and international law: a contemporary analysis. Economic and Political Weekly, v. 34, n. 6, p. 337-349, Fev. 6-12, 1999.

CHIMNI, B. S. The past, present and future of international law: a critical third world approach. Melbourne Journal of International Law, v. 8, n. 2, p. 499- 515, 2007.

COMISSÃO ECONÔMICA PARA A AMÉRICA LATINA E O CARIBE. Os povos indígenas na América Latina: avanços na última década e desafios pendentes para a garantia de seus direitos. Santiago do Chile: Nações Unidas, 2015.

CRAWFORD, James. The rights of peoples: 'peoples' or 'governments'? In: (Ed). The rights of peoples.

Oxford: Oxford University, 2001. p. 55-68.

CUMBERLAND, Emily. Call for Submissions for Symposium on Third World Approaches to International Law (TWAIL). Washington: American Society of International Law, March 2015. Available in: <http://www.asil. org/blogs/call-submissions-symposium-third-worldapproaches-international-law-twail>. Access: Jan. 22, 2016.

DULITZKY, Ariel E. Quando os afrodescendentes se tornaram "povos tribais": o sistema interamericano de direitos humanos e as comunidades negras rurais. Meritum, Belo Horizonte, v. 6, n. 2, p. 57-138, jul./dez. 2011.

ENGLE, Karen. The elusive promise of indigenous development: rights, culture, strategy. Durham: Duke University, 2010.

ESLAVA, Luis; PAHUJA, Sundhya. Beyond the (post) colonial: TWAIL and the everyday life of international law. Journal of Law and Politics in Africa, Asia and Latin America, v. 45, n. 2, p. 195-221, 2012.

FATOUROS, A. A. International law and the third world. Virginia Law Review, v. 50, n. 05, p. 783-823, jun. 1964.

FITZPATRICK, Peter; DARIAN-SMITH, Eve. The laws of the postcolonial: an insistente introduction. In: (Eds.) Laws of the Postcolonial. Ann Arbour: Uni- 
versity of Michigan Press, 1999. p. 1-18.

FLORY, Maurice. Adapting international law to the development of the Third World. Journal of African Law, v. 26, p. 12-20, 1982.

GALINDO, George Rodrigo Bandeira. A volta do terceiro mundo ao direito internacional. Boletim da Sociedade Brasileira de Direito Internacional, v. 1, n. 119-124, p. 46-68, ago./dez. 2013.

GALINDO, George Rodrigo Bandeira. Para que serve a história do direito internacional? Revista de Direito Internacional, Brasília, v. 12, n. 1, p. 338-354, 2015.

GATHII, James Thuo. TWAIL: a brief history of its origins, its decentralized network, and a tentative bibliography. Trade Law and Development, v. 3, n. 1, p. 27-64, 2011.

GORDON, Seth. Indigenous rights in modern international law from a critical third world perspective. American Indian Law Review, v. 31, p. 401-424, 2006.

KINGSBURY, Benedict. Reconciling five competing conceptual structures of indigenous peoples' claims in international and comparative law. New York University Journal of International Law and Policy, v. 34, p. 189-250, 2001.

KOSKENNIEMI, Martti. Empire and International Law: the real spanish contribution. University of Toronto Law Journal, v. 61, p. 01-36, 2011.

KOSKENNIEMI, Martti. The gentle civilizer of nations: the rise and fall of international law 1870-1960. Cambridge: Cambridge University, 2004.

KUMAR, Vidya S. A. A proleptic approach to postcolonial legal studies? a brief look at the relationship between legal theory and intellectual history. Law, Social Justice and Global Development Journal, n. 2, 2003. Available in: <https://www2.warwick.ac.uk/fac/soc/law/elj/ lgd/2003_2/kumar>. Access: Jan. 22, 2016.

LORCA, Arnulf B. International law in Latin America or latin american international law? rise, fall, and retrieval of a tradition of legal thinking and political imagination. Harvard International Law Journal, v. 47, n. 1, p. 283-305, Winter 2006

LUDDEN, David (Org). Reading subaltern studies: critical history, contested meaning and the globalization of South Asia. London: Anthem, 2002.

LUNDIN, John. Climate change: is it the indigenous peoples who have the answers? July, 2013. Available in: <http://thedemocraticdaily.com/2013/07/27/ climate-change-indigenous-peoples-answers/\#sthash. NoEZmviQ.AaXfsjOi.dpuf>. Access: Set. 01, 2015.

MÉGRET, Frédéric. International law as law. In: CRAWFORD, J.; KOSKENNIEMI, M. (Ed.). The Cambridge companion to international law. Cambridge: Cambridge University, 2012. p. 64-92.

MIRANDA, Lillian Aponte. Indigenous peoples as international lawmakers. Journal of International Law, v. 32, n. 1, p. 203-263, 2010.

MIRANDA, Lillian Aponte. The hybrid state-corporate enterprise and violations of indigenous land rights: theorizing corporate responsibility and accountability under international law. Lewis e Clark Law Review, v. 11, n. 01, p. 135-183, 2007.

MUNARRIZ, Gerardo J. Rhetoric and reality: the world bank development policies, mining corporations, and indigenous communities in Latin America. International Community Law Review, v. 10, p. 431-443, 2008.

MUTUA, Makau. What it TWAIL? In: ANNUAL MEETING AMERICAN SOCIETY OF INTERNATIONAL LAW, 94., Washington, 2000. Proceedings...Washington: ASIL, 2000. p. 31-39.

NAÇÕES UNIDAS. Declaração das Nações Unidas sobre os Direitos dos Povos Indígenas. Rio de Janeiro, 2008. Disponível em: <http://www.un.org/esa/socdev/unpfii/ documents/DRIPS_pt.pdf>. Acesso em: 20 out. 2015.

OKAFOR, Obiora C. Critical third world approaches to international law (TWAIL): theory, methodology, or both? International Community Law Review, v. 10, p. 371378, 2008.

ORFORD, Anne. Ritual, Mediation and the International Law of the South, Griffith Law Review, v. 16, p. 353374, 2007.

PAHUJA, Sandhya. The postcoloniality of international law. Harvard International Law Journal. v. 46, n. 2, p. 459469, summer 2005.

PARMAR, Pooja. TWAIL: an epistemological inquiry. International Community Law Review, v. 10, p. 363-370, 2008.

PASQUALUCCI, Jo M. International Indigenous Land Rights: a critique of the Jurisprudence of the InterAmerican Court of Human Rights in light of the Uni- 
ted Nations Declaration on the Rights of Indigenous Peoples. Wisconsin International Law Journal, v. 27, n. 01, p. 51-98, 2009.

PASQUALUCCI, Jo M. The evolution of international indigenous rights in the inter-american human rights system. Human Rights Law Review, v. 6, n. 2, p. 281-322, 2006.

RAJAGOPAL, Balakrishnan. International law and social movements: challenge of theorizing resistance. Columbia Journal of Transnational Law, v. 41, n. 2, p. 396-433, 2003.

RAJAGOPAL, Balakrishnan. Locating the Third World in Cultural Geography. Third World Legal Studies, v. 15, n. 2, p. 01-20, 1999.

RAJAGOPAL, Balakrishnan. Postdevelopment as a vision for a third world approach to international law. In: ANNUAL MEETING AMERICAN SOCIETY OF INTERNATIONAL LAW, 94., Washington, 2000. Proceedings...Washington: ASIL, 2000. p. 306-307.

RATNER, Steven; SLAUGHTER, Anne-Marie. Symposium on method in international law: appraising the Methods of International Law: a prospectus for readers. American Journal of International Law, Washington, v. 93, n. 2, p. 291-302, 1999.

SAID, Edward W. Cultura e imperialismo. Trad. Denise Bottmann. São Paulo: Companhia das Letras, 2011.

SAUVY, Alfred. Trois mondes, une planete. L'observateru, Paris, n. 118, p. 14, 14 aout 1952. Disponible dans: <http://www.homme-moderne.org/societe/demo/ sauvy/3mondes.html>. Accès: 06 out. 2015.

SHAW, Malcolm N. International Law. 6. ed. Cambridge: Cambridge University, 2008.

SHOEMAKER, N. A Typology of Colonialism. Available in: <http://historians.org/publications-and-directori- es/perspectives-on-history/october-2015/a-typologyof-colonialism\#.VinyWqK7OG4.facebook>. Access: Oct. 24, 2015.

SINGH, Prabhakar. Indian international law: from a colonized apologist to a subaltern protagonist. Leiden Journal of International Law, v. 23, p. 79-103, 2010.

STAVENHAGEN, Rodolfo. Relatório sobre a situação dos direitos humanos e liberdades fundamentais dos povos indigenas. 2003. Disponível em: <http://www.unhchr.ch/huridocda/huridoca.nsf/e06a5300f90fa023802566870051 8ca4/30f0fcfc1eb1b247c1256d09003152b2/\$FILE/ G0310544.pdf>. Acesso em: 14 out. 2015.

UNITED NATIONS EDUCATIONAL, SCIENTIFIC AND CULTURAL ORGANIZATION. At Geneva meeting, UNESCO affirms its commitment to indigenous peoples Rights. 2015. Available in: <http://www.unesco. org/new/en/media-services/single-view/news/at_geneva_meeting_unesco_affirms_its_commitment_to_ indigenous_peoples_rights/\#.VhVJJvlViko>. Access: Set. 01, 2015.

UNITED NATIONS. Declaration on the Establishment of a New International Economic Order. May. 1974. Available in: <http://www.un-documents.net/s6r3201.htm>. Access: Feb. 4, 2016.

UNITED NATIONS. Declaration on the Right to Development. 4 Dec. 1986. Available in: <http://www. un.org/documents/ga/res/41/a41r128.htm>. Access: Feb. 4, 2016.

UNITED NATIONS. State of the worlds indigenous peoples. New York: United Nations, 2009. Available in: <http:/ / issuu.com/uniccanberra/docs/state_of_world_s_indigenous_peoples/1>. Access: Oct. 05, 2015.

VITÓRIA, Francisco de. Os indios e o direito da guerra. Trad. Ciro Mioranza. Ijuí: Editora Ijuí, 2006. (Clássicos do Direito Internacional). 
Para publicar na Revista de Direito Internacional, acesse o endereço eletrônico www.rdi.uniceub.br ou www.brazilianjournal.org.

Observe as normas de publicação, para facilitar e agilizar o trabalho de edição. 